\title{
COMPLETE HEART BLOCK
}

\author{
BY \\ MAURICE CAMPBELL \\ From Guy's Hospital and the National Hospital for Diseases of the Heart \\ Received October 21, 1943
}

This paper discusses 64 cases of heart block, mostly complete, seen during the same period as 29 cases with dropped beats and 140 cases with latent heart block (Campbell, 1943, $b$ and $c$ ).

Of the patients attending the Cardiographic Dept., Guy's Hospital, during 12 years, 0.6 per cent had complete, 0.5 per cent partial, and 2.2 per cent latent heart block. Comeau (1937) found 0.55 per cent of cardiovascular cases had complete block; and Paul White (1937) found 0.8 per cent had complete, 2.6 per cent partial, and 3.0 per cent latent. It is curious that with such close agreement between the other figures he should have found so many more with partial block.

An analysis of the age and sex of the cases and of their actiology was similar to that found in other series, so this and the clinical features will be dealt with shortly. Three aspects will be dealt with rather more fully-the prognosis, the incidence and significance of StokesAdams attacks, and the extent to which complete block remains persistent or varies to lower grades of partial or latent block. 'This leads to a more complete classification of the subdivisions of heart block.

I had the impression that, apart from the cases in hospital with frequent changes of rhythm . and Stokes-Adams attacks, complete heart block was as a rule persistent once it had been found. But half my cases had more than one grade of heart block graphically recorded; and more than 60 per cent were observed clinically to have such changes. Sometimes these were frequent and one did not know with what rhythm the patient would be seen next: sometimes, after a long period of complete block, partial or latent block was seen for no apparent reason. •

\section{Aetiology}

Sex incidence. There were 51 men and 13 women, a preponderance of $4: 1$. If the 3 rheumatic cases (all women) were excluded the proportion rose to $5: 1$. Graybiel and White (1936) found the proportion $2: 1$; and all observers are agreed that it is much more common in men.

This is another contrast between complete and lower grades of heart block where the difference of sex incidence is absent or much less marked. In my 38 cases with dropped beats, 19 were men and 19 were women, and this applied as much to the elderly myocardial group as to the younger patients with rheumatic and other infectious diseases. In the 31 cases with latent block with a P-R interval over $0.26 \mathrm{sec}$. or more there was a preponderance of males, but it was entirely in the elderly group. There were 19 younger patients (average age 24) with rheumatic and other diseases, and here there were 11 males and 8 females: there were 12 older patients with myocardial disease (average age 56), and here there were 10 men and 2 women-the same proportion as with complete block.

Age incidence. The age, reckoned from when they were first seen (and generally this seemed to be near the time of onset), is shown below.

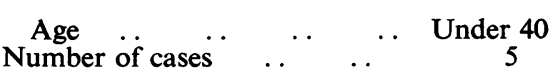

F

$\begin{array}{cc}40 \text { to } 49 & 50 \text { to } 59 \\ 5 & 17\end{array}$


Most patients (45 per cent) were between 60 and 69, and 84 per cent were over 50 . In the small number under 40 , the prognosis seemed to be better, but otherwise the age did not seem to be important. The better prognosis at the younger age would, of course, be made much more striking had congenital cases been included. A more detailed analysis is given in Table I. Originally those with and those without latent block were listed separately, but as there was no significant difference they have been combined.

TABLE I

Age of Patients with Heart Block (Age when First Seen)

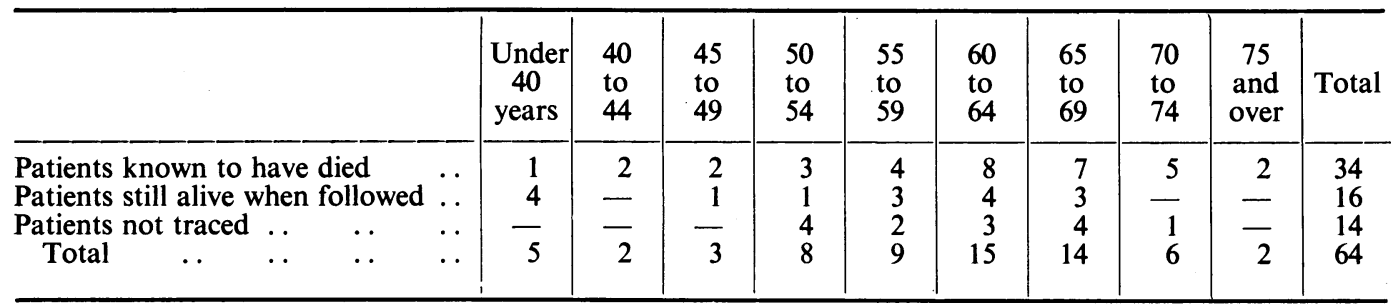

Etiology. Myocardial disease without any evidence that it was rheumatic or syphilitic was much the most common cause- 86 per cent of all cases, or 76 per cent if congenital cases were included. The congenital cases, which have been excluded otherwise from this paper as they have already been reported (Campbell, 1943a), were the second commonest group, forming 13 per cent of the total, while the rheumatic and syphilitic groups together formed only just over 11 per cent.

The figures found in the series collected by Graybiel and White (1936) were so similar that I have included them for comparison in Table II. The only significant differences were that - they have included a few cases in a diphtheritic group, of which I have not found any examples, and had left more cases as due to combined causes (where I had more dogmatically placed the case in one group or the other according to the factor that seemed most important), and that ${ }^{\circ} \mathrm{I}$ had more congenital cases. The average ages of the different ætiological groups have also been added.

TABLE II

Aetiology of Complete Heart Block

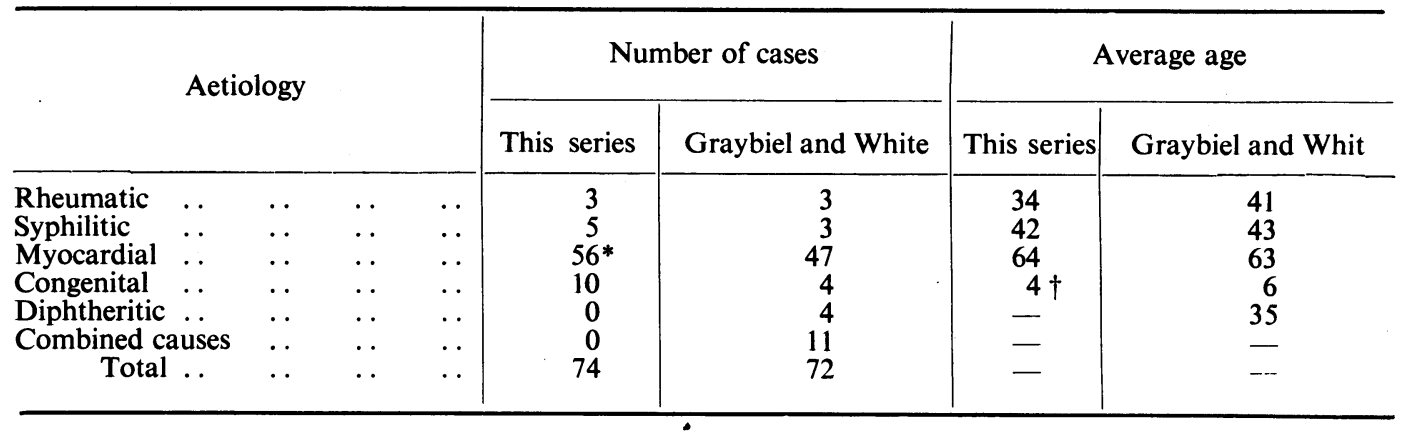

* High blood pressure, 10; coronary atheroma, 17; cardiac failure, 4; and cardiac enlargement generally with atherosclerosis without the previous features, 25.

$\dagger$ The present age of the seven known to be alive is 30 years.

High blood pressure has not been taken as a separate main division and my evidence for calling a case myocardial must be given. Of the 56, 10 had high blood pressure (over 160/100). In several others the systolic pressure was high, but as this seems to rise in many-but by no 
means all-cases to compensate for the long diastole, this was not counted until the diastolic pressure was also raised; 17 were included as having coronary arterial disease and the evidence for this was a history of angina pectoris or cardiac infarction; and 6 had congestive heart failure without high blood pressure or evidence of coronary disease.

The remainder had enlargement of the heart without these other findings: it is surprising that cardiac enlargement was the only other decisive evidence of heart disease in 23 of the 56, though many had thickened radial or retinal arteries and still more had signs of atherosclerosis of the aorta on radioscopy. It is surprising and significant that so many patients with complete heart block seem relatively well and are able to lead quiet lives, almost normal for their age, provided they do not suffer from Stokes-Adams attacks. One common type is the elderly man with grey hair and thickening arteries who has led a strenuous and sometimes intellectual life, often with hardly a day's illness.

The rheumatic cases were few: one with mitral disease had varying grades of heart block that were occasionally complete (Case 107, p. 80), one had temporary block during active rheumatic carditis (Case 113, p. 83), and one was called rheumatic on a history of rather doubtful rheumatism in childhood (Case 140, appendix). Their average age was 34 years. Perhaps a fourth should have been included, but on his age of 68 , on the late onset of any symptoms before his congestive failure, and on the signs being predominantly those of aortic stenosis, he was included as atherosclerotic though he had also some aortic incompetence and a history of rheumatic fever 38 years before (Case 150). The two other cases with aortic stenosis are referred to on p. 76.

Case 150. A man, aged 68, had rheumatic fever when he was 30 . He got on well, though with increasing dyspnœa as he got older, till at 68 he was admitted to hospital with congestive heart failure. $\mathrm{He}$ was found to have aortic stenosis and incompetence, C.H.B., B.B.Bl., and auricular fibrillation (Fig. 1); his B.P. was 190/60; his W.R., negative. He improved for a time but died five months

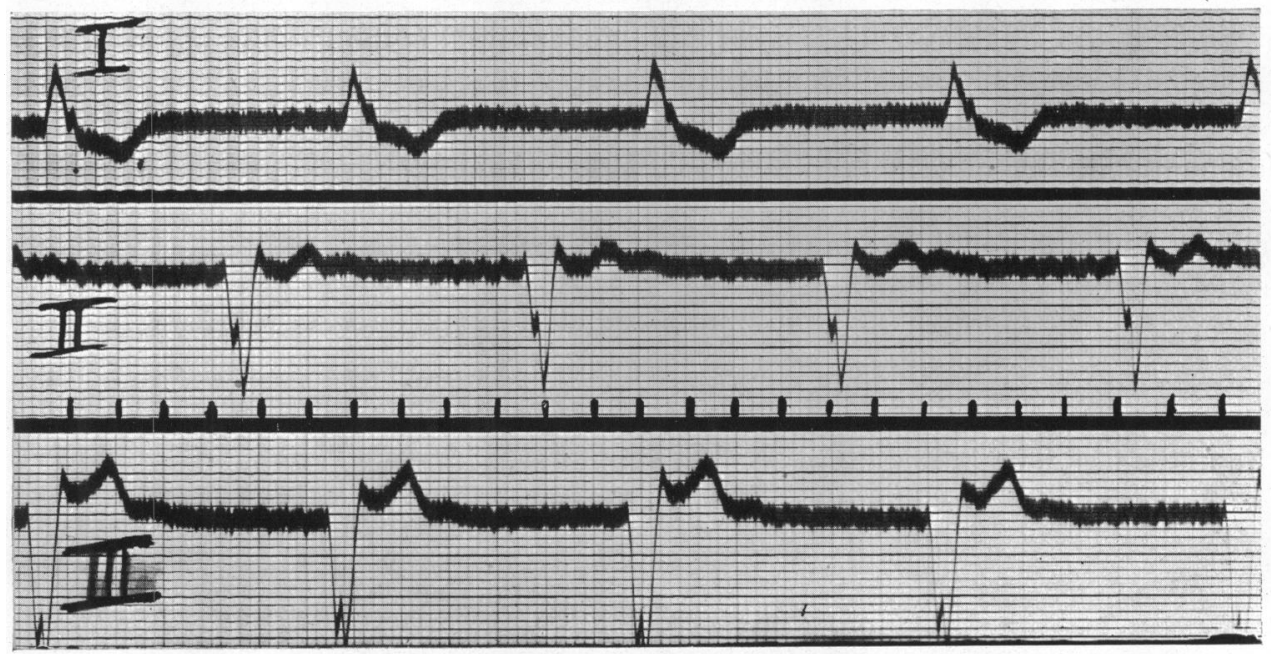

FIG. 1.-A faster rate than usual, in an old man with atherosclerosis are aortic stenosis. His rate averaged 48 and was 47 a minute in this record, when he had also, as usual, bundle branch block and auricular fibrillation (Case 150). In this and most subsequent figures the inked marks indicate $1 / 5$ th sec.

later, after developing coupled beats of an irregular type, probably as the result of treatment with digitalis (Fig. 2). Post-mortem, there was left ventricular hypertrophy with extreme calcification of the coronary arteries. There was calcified thickening of the aortic cusps and old fibrosis of the mitral valve.

The striking thing about the syphilitic cases was that none had the usual signs of aneurysm or gross aortic incompetence. One only had a slight aortic leak and he gave no history of syphilis and had a negative Wassermann reaction (W.R.) (Case 123, appendix). One was 


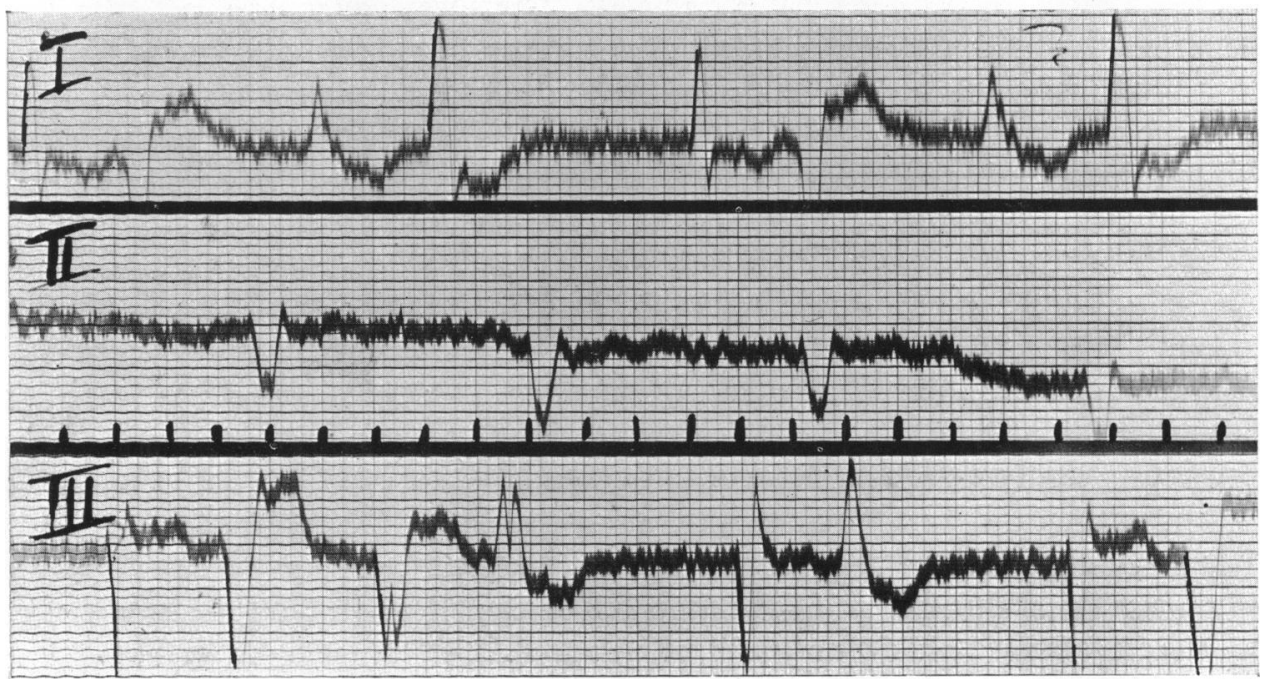

FIG. 2.-Bigeminy of an irregular type from the same patient as Fig. 1. It was taken some months later, shortly before his death, and may have been partially due to digitalization. In lead II there is C.H.B. with a still faster rate of 54 a minute; in leads I and III, bigeminal extrasystoles of different types and also changes in the bundle conduction.

included on a positive W.R. and signs of neurological syphilis though his blood pressure was 250/130 (Case 101, p. 83). One was included on a positive W.R. only (Case 138). One may have had congenital syphilis as her father had died with general paralysis of the insane, but there were no other signs of this and her.W.R. was negative (Case 159, appendix). The last, aged 34, was included on the sole evidence of a weakly positive W.R. (Case 108, p. 81). The average age of these five patients was 42 . Even in these cases it will be agreed that it was not really certain that the heart block was caused by syphilitic disease.

There were three others where this diagnosis had to be considered. One had a positive W.R. but also had a blood pressure of 210/130 and albuminuria, and post-mortem his heart weighed $900 \mathrm{~g}$. and there was no evidence of syphilitic disease (Case 120, p. 81). Two others had angina and arteriosclerosis and were classified as this, although one had a positive W.R. (Case 104) and the other a history of syphilis with a negative W.R. (Case 119), because there was no evidence on radioscopy or otherwise of syphilitic disease.

A possible explanation of the absence of typical syphilitic cases is that these develop in the quaternary stage of the disease, and that heart block, when it is syphilitic, is more likely to arise in the tertiary stage as the result of a gumma affecting the A-V bundle.

There is unusual doubt about how many of these cases should be included, but if every doubtful case were included as rheumatic or syphilitic the incidence would only be increased to 5 and 10 per cent respectively.

\section{Stokes-Adams AtTacks}

Stokes-Adams attacks are found in about half the patients who attend hospital with complete heart block, and probably this gives a true picture of their incidence. When present they form the most striking part of the clinical picture. They may be few and far between, or very frequent, or frequent at first and rare or absent later.

The patient who has not had an attack when first seen need not, however, be unduly alarmed about them. Probably he will never have an attack, and after six months freedom, their onset becomes much less likely (see p. 74). His outlook must therefore be judged on the presence of congestive failure, angina pectoris, etc. Except for the statistical evidence 
that follows I have no help to give for the prognosis of those who have these most alarming and unpredictable attacks.

It is not easy to decide exactly what should be included as Stokes-Adams attacks. Should the minor attacks in which consciousness is not lost be included, as these are obviously due to the same mechanism but of shorter duration? Should similar attacks in patients without heart block be included? In order to give a precise meaning to the term, I think they should not and would accept the definition of Parkinson, Papp, and Evans (1941): attacks of loss of consciousness due to ventricular standstill, ventricular tachycardia, ventricular fibrillation, or a combination of these, in a patient with heart block. It is most important to add that the heart block may be established or paroxysmal, and as the paroxysmal heart block may only occur for a short time after the attack, the diagnosis must sometimes be made on clinical grounds only without a proof of the heart block when no precise record of the behaviour of the heart during and after the paroxysm is available. The attacks are of two main forms, syncopal or epileptiform, this probably depending on the duration of the arrest of the heart's action.

It is sometimes thought that the onset must be absolutely sudden, as it obviously is in most patients who fall so that they hurt themselves. But in some patients a shorter arrest of the heart's action - too short to produce a true attack-would produce a feeling of faintness and other symptoms; and in such patients these symptoms will often be present as an aura to the fully developed attack. By chance the first two patients quoted by Parkinson et al. illustrate these two possibilities, and we have many examples.

Case 4 of Parkinson et al. proves, if further proof were needed, that the minor attacks are of the same nature. After various symptoms "he expected to faint but only turned pale and breathed rapidly. In some of them the pulse stopped and the ventricles ceased beating for 5 seconds or more." . . . " In almost as many attacks consciousness was lost and the ventricular standstill lasted 10-20 seconds, the patient becoming unconscious towards the middle of this period."

This paper of Parkinson, Papp, and Evans has dealt so fully with the actual behaviour of the heart during the attacks that $I$ have nothing to add except a description of one case of Dr. Suzman's (see appendix). But in most cases cardiographic records are not available and the diagnosis must be made on the story. Generally there is not much difficulty in patients with the classical abrupt onset who fall and hurt themselves, unless the heart block is missed because it is paroxysmal. But the preliminary aura may lead to confusion with fainting attacks, vaso-vagal attacks, or even hysteria, though the sensible matter-of-fact patient generally prevents this.

The aura may be very variable and a few random examples are given in the patients' own words. "Can't breathe, pins and needles all over the body, then remember nothing" (Case 107). "Feel rushing in the ears, then dazed for a few seconds, then trembling, then all right again-would fall down if I had nothing to hold, and can sometimes remember the actual fall" (Case 108). " Go blind, feel queer and giddy and as though my heart has stopped, and then fall down unconscious" (Case 130). [I have put some of these words in italics because $I$ think that many patients are remarkably aware of visceral happenings, and that some doctors are not ready to pay enough attention to the patient's description of his sensations, on which most of our diagnosis rests.] " Severe precordial pain passing up the left side to the lower angle of the jaw, then fall unconscious" (Case 142).

Case 123 (appendix) gave a most curious story and no diagnosis was made for years ; even when he developed heart block I did not feel sure of the nature of his attacks which were probably associated with paroxysmal heart block at first, until I had become more familiar with this condition.

It is sometimes said that biting the tongue and incontinence of urine or fæces are diagnostic of epilepsy and exclude Stokes-Adams attack. This is not so, though these events are rare 
in Stokes-Adams attacks and common in epilepsy. In Case 7 of Parkinson et al. there was incontinence of urine and in Case 6 incontinence of fæces. The occurrence of tongue biting and incontinence of urine in my Case 142 can not therefore establish the original diagnosis of epilepsy that was made in this patient. Probably the duration of the ventricular standstill is the decisive factor.

Minor attacks. Between true Stokes-Adams attacks and the attacks of faintness and giddiness that are not included as such, there are minor attacks which have the same relationship to true attacks as petit mal to grand mal. Case 116 provided a good example. In one major attack he "felt it coming, but had no time to get to the railings and fell and cut his head." In a minor attack he " felt a little funny on his way home from work, had a momentary blank, but the paper did not fall from under his arm."

It is not easy to see why there should be such a variety of symptomatology. In epilepsy the varying auras can be explained by different spreads of the nervous impulses through the brain, but in Stokes-Adams attack the heart is at fault and one might guess the central effect in the brain would always start and spread in the same way. But patients with Stokes-Adams attacks have generally atherosclerosis, and probably different degrees of atheroma in different cerebral vessels influence the effect that ventricular standstill has on the functions of the brain.

Presenting symptoms. There was a striking difference in the presenting symptoms of those with and of those without Stokes-Adams attacks. Most of the latter were first seen for dyspnœa or attacks of faintness or giddiness.

Of the former, 21 (63 per cent) were first seen because of the Stokes-Adams attacks and they had no serious cardiac symptoms before this. It does not, of course, follow that the attack was actually at or near the onset of complete heart block (C.H.B.) but it seems likely that this was so in many cases; 2 others had coronary thrombosis which was quickly followed by C.H.B. and Stokes-Adams attacks, though in one of these the slow pulse was noted the day before the first attack.

There were, on the other hand, 8 cases where the heart block was known to have been present for a reasonable period before there was a true Stokes-Adams attack: 6 of these had attacks of faintness or dizziness as the first presenting symptom, 1, 1, 3, 4, 8, and 24 months before respectively (" last two years have had several giddy turns, too many to count; last week fell and cut my head ", Case 116); one other complained of dyspnœa only and 6 months later had his first attack, and the eighth came to hospital for gangrene of his leg and had his first attack 7 weeks later.

The remaining 2 cases were under observation for dyspnœa and angina before they developed C.H.B. The former was readmitted to hospital with congestive failure and C.H.B. and the first attacks which soon proved fatal followed 5 months later (Case 120). The latter was found to have C.H.B. five weeks after her first Stokes-Adams attack and as this was the first time she had been seen since the attack it probably indicated the origin of the C.H.B. (Case 118, p. 81).

Thus the Stokes-Adams attacks were the first significant symptom of C.H.B. in 72 per cent; and in 27 per cent the C.H.B. was known to have been present, or other symptoms made this likely, for an average period of 6 months before there was a Stokes-Adams attack.

The exact onset of complete heart block is often unmarked by any specific symptom where the patient does not suffer from a Stokes-Adams attack. In certain patients, however, it can be recognized, and I have three histories where there was some confirmatory evidence. "Sudden thumping in the ears, nearly lost control, but was not unconscious"; his doctor found the slow pulse the same afternoon (Case 134). "Started with onset of giddiness, nearly fell down, noticed breathlessness the same day" (Case 162). "Attacks of flushing, giddiness, and discomfort, without loss of consciousness, starting when my heart became 
slow." This should be accepted, as after six years of established complete heart block she came to hospital one afternoon saying that her heart had gone back to its normal rate and this was found to be the case $(\mathrm{P}-\mathrm{R}, 0.23 \mathrm{sec}$.), but it did not persist: high blood pressure may have made her unusually aware of her heart rate (Case 125). Of the 31 who had not Stokes-Adams attacks, dyspnœa (10 cases) or faint or giddy attacks (12 cases) were almost equally common presenting symptoms, and between them accounted for 70 per cent of the cases. Of the others, three had congestive failure, one angina pectoris, and one coronary thrombosis. In the remaining four the presenting symptoms were varied and often noncardiac and the finding of complete heart block was a surprise.

\section{Other Features of the Clinical Piçtúre}

Heart rate. This was carefully analysed in 30 patients in whom I had frequent records over a reasonably long period-sometimes for many years. Taking an average figure for each case, the results are shown in Table III.

TABLE III

Heart Rate in Complete Heart Block

$\begin{array}{llllllllll}\text { Heart rate } & . . & . & \text { Under } 24 & 24 \text { to } 27 & 28 \text { to } 31 & 32 \text { to } 35 & 36 \text { to } 39 & 40 \text { to } 43 & 44 \text { and above } \\ \text { Number of cases } & \ldots & 1 & 3 & 6 & 4 & 9 & 5 & 2\end{array}$

In the great majority the average rate was between 28 and 40 with a grand average of 34.6 a minute. This is slower than the rate of 38-40, given by Graybiel and White (1936) and I think more in accord with general experience. Of course there was variation in an individual case from time to time, and typical figures were $24-30,28-36,32-40$, and $36-42$; in the two patients in whom there were the largest number of observations over many years, the range was 32-44 with two single readings of 45 and 54, and 28-40 with an average figure of $34 \cdot 8$.

The specially fast and slow rates were considered for all the patients. Two had average rates of 24 (Cases 144 and 146) and both were. specially liable to feeling faint and giddy apart from their true Stokes-Adams attacks. One, who died three days later in a Stokes-Adams

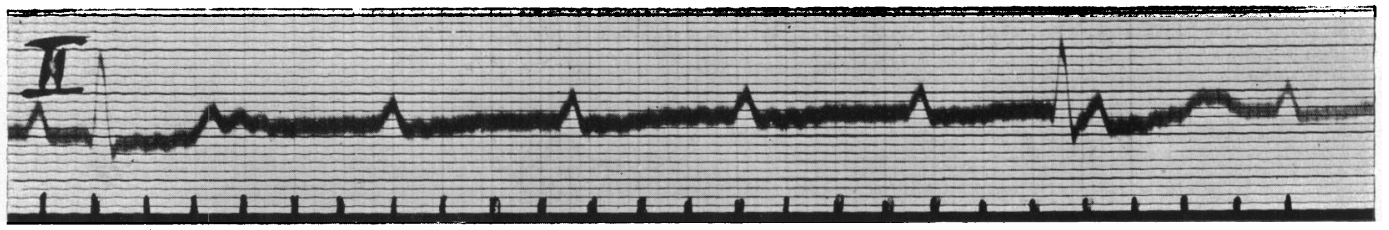

FIG. 3.-An unusually slow rate in complete heart block. His rate, clinically, was often 18-20 and here in lead $I$ it was as slow as $15 \cdot 8$ a minute (Case 155 ).

attack, had a rate of 18-20 and sometimes a cardiographic rate of 17 (Fig. 3); curiously enough he did not complain specially of any symptoms while this record was taken (Case 155).

In several patients a slower rate than their usual one was often associated with regular bigeminal ventricular extrasystoles (Fig. 4) and was perhaps their cause, though it is not clear how they arise in complete heart block. For example, one whose rate was generally $32-44$ had a rate of 56 with alternating extrasystoles, i.e. a true rate of 28 ; and another whose usual rate was $28-40$ had alternating extrasystoles when the rate without these would have been 22 .

Rates over 44 were rather more common but there were special features about the four patients in whom these were found regularly at rest. A girl, aged 18, is reported in the appendix (Case 159). In a young woman, whose heart block was temporary and due to acute rheumatic carditis, the rate was 62 (auricle 115) (Case 113, p. 83); this rapid rate with complete heart block is well known in diphtheria. 


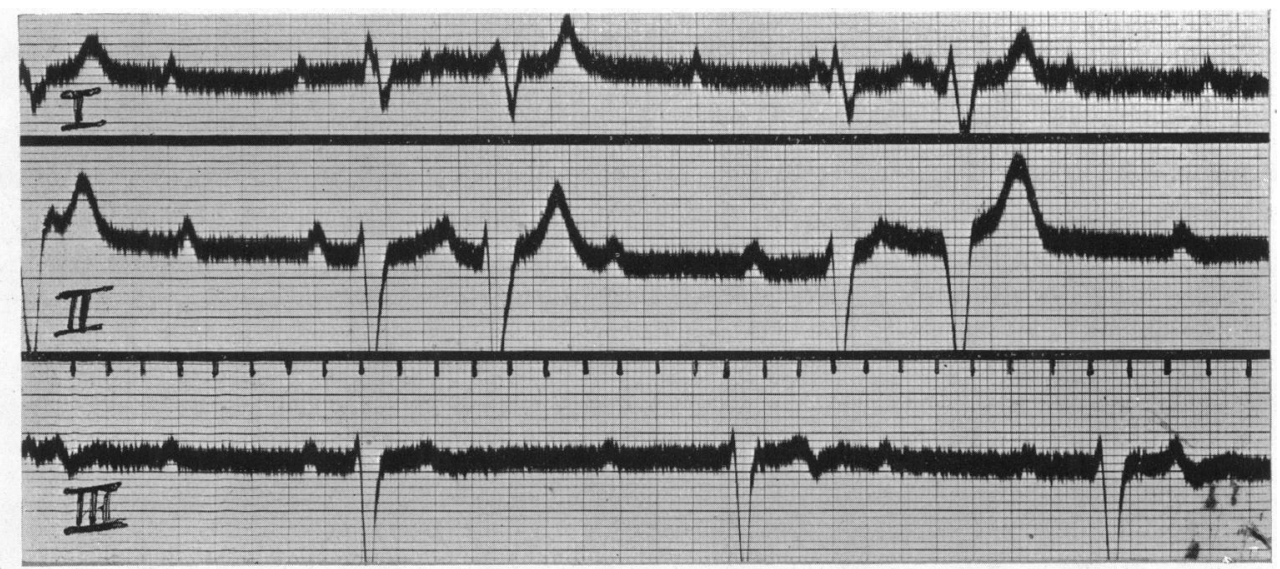

FIG. 4.-Regular bigeminal extrasystoles with complete heart block. In lead III the ventricular rate is a little faster and there are no extrasystoles (Case 132).

In two cases with aortic stenosis and incompetence, the rate was between 36 and 50 in Case 126 (p. 81), and in Case 150 (p. 71) it averaged 48. These suggest that with aortic stenosis the rate tends to be faster, but in the only other patient with aortic stenosis, a man of 63 with high blood pressure, the rate was 34-42 (Case 102, p. 81). All these three had B.B.B1. also.

Heart rate after exercise. It is generally thought that there is not much change in the heart rate with exercise in cases of complete heart block. Often this is true, at any rate with the gentle exercise they are able to take, and the rise is no more than a few beats a minute. Case 108, for example, showed very little increase even when the auricular rate was doubled. At the other extreme Case 159 showed an increase from 46 to 60 and sometimes to 70 (details are given in the appendix): In congenital complete heart block, where seven cases were tested, I found an average increase from 48 to 55, or to 64 if the rate was calculated from the first quarter-minute only. Even in some of the elderly patients with atherosclerotic complete heart block there may be considerable increases, e.g. in Case 132 the rate was increased from 38 to 58 a minute. Here there was also a change in the type of ventricular complexes (Fig. 5 and 6), but this is, of course, not usual. In the patients with varying degrees of heart block the result of exercise was not easy to foretell. In Case 142 with 2: 1 block the auricular rate

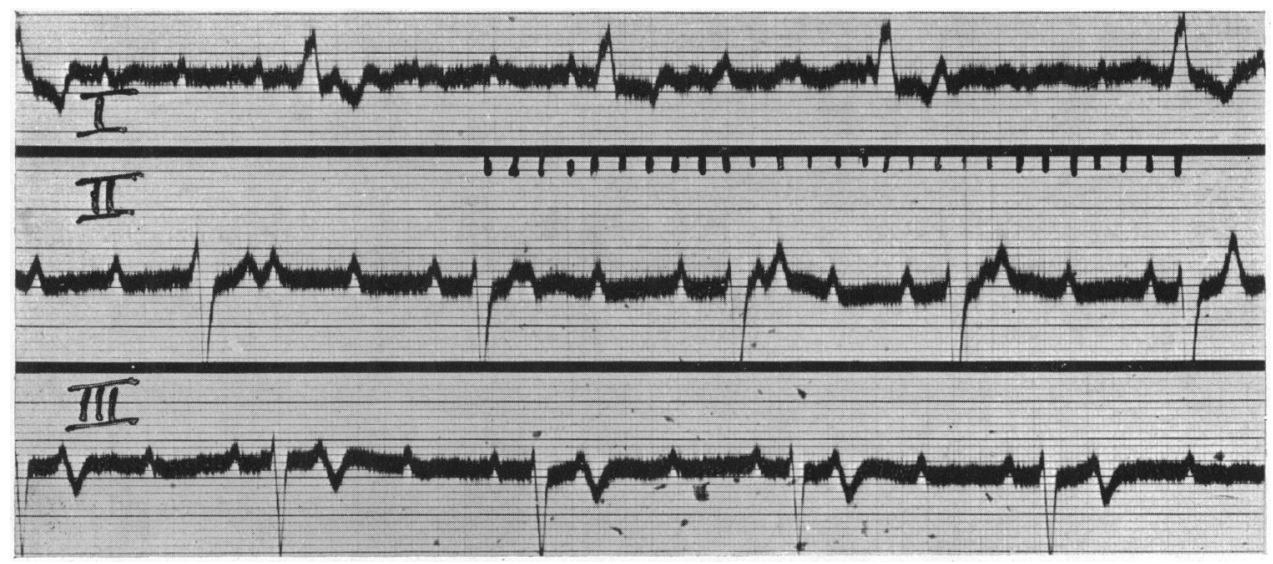

Fig. 5.-Complete heart block with a ventricular rate of 38 from a man, aged 59, who was under regular observation for five years. His B.B. was $200 / 100$ and his W.R. was negative. He had five Stokes-Adams attacks in the first two years, but after taking pot. iod. regularly was three years without an attack except once when he had stopped it for 6 weeks. (Case 132, see also Fig. 6.) 


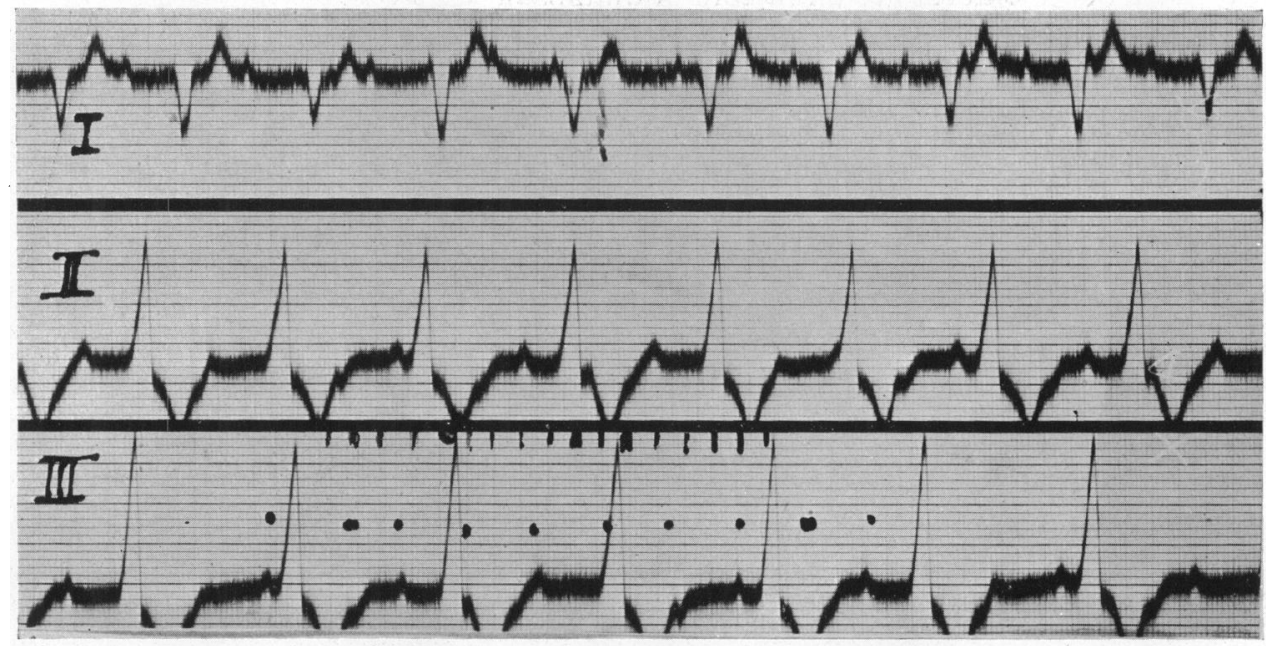

Fig. 6.-Complete heart block from the same case as Fig. 5 with a much faster ventricular rate (58) and a change in the ventricular complexes after exercise. This change was produced on several occasions with exercise (Case 132).

was increased from 70 to 124 while $2: 1$ block was still maintained. In Case 145, $2: 1$ block before exercise changed to complete block after it, but on another day complete block before exercise changed to $4: 1$ block after it.

The blood pressure. The cases were classified as hyperpietic where the systolic pressure was over 160 and the diastolic over 100 . In these 10 , the average blood pressure was $225 / 108$. This is a high pulse pressure as more common averages for ordinary cases of hyperpiesis would be $225 / 130$ or $180 / 108$.

Of the much larger number of cases not falling into this classification of high blood pressure, there were by chance almost exactly equal numbers with a systolic pressure above and below 160. In the former the average figure was $194 / 81$ and in the latter $137 / 73$. Roughly speaking one could say that in half there was a high pulse pressure (about 100) and a high systolic pressure with a normal diastolic pressure, and that in half all three were normal, perhaps with a slightly raised pulse pressure. A more detailed analysis, putting the cases into eight equal groups according to the height of their systolic pressure, gave the following average figures: $224 / 82,195 / 86,187 / 80,169 / 75,150 / 81,141 / 77,134 / 70$, and 121/65.

The slow forceful heart beat with its long diastole has been said to produce a high systolic pressure to maintain the circulation adequately and, with more certainty, some fall in the diastolic pressure. This is no doubt part of the explanation but does not seem to be the whole, as half the cases showed so little increase of pulse pressure. Possibly, for this reason, some additional cases should be classified as hyperpietic, because originally they had a higher diastolic pressure, i.e. above 100 , but we have no direct evidence of this having happened except perhaps in Case 142 where an early pressure of about 170/97 seemed to have settled at $235 / 88$ six years later.

Probably a more important factor is the atherosclerosis of the aorta that is such a marked feature of many of these cases, though not to a greater extent than in many elderly men. Although several writers have pointed out that as the aorta becomes less elastic a greater pulse pressure is needed to stretch it enough to accommodate the same stoke volume with each heart beat, the significance of this as a cause of a high systolic and high pulse pressure is still insufficiently recognized. It follows from the known physiological facts that the systolic pressure must rise greatly as the elasticity of the aorta diminishes, if the output of the heart is not to fall. This automatically increases the work of the heart. In many elderly patients the diminished output, the increased systolic pressure, and the increased work of the 
heart in stretching the aorta are all factors in diminishing the capacity for effort quite apart from any rise of diastolic pressure due to true hyperpiesis which would further accentuate the difficulty.

Bundle branch block. There was some association between bundle branch block (B.B.BI.) and the lower grades of heart block, nearly 4 per cent of those with latent block having B.B.Bl. There is a closer association between B.B.Bl. and complete heart block. Of the 64 cases, 13 had typical, and 6 others somewhat atypical, B.B.Bl., the combined figures being nearly 30 per cent; in addition another 8 had widened QRS complexes that did not amount to B.B.Bl. In a few cases the B.B.Bl. was irregular, being sometimes present and sometimes absent. In some who had both latent and complete block, there were various findings: B.B.Bl. with C.H.B. and not with N.R. (Case 126, see Table VI), B.B.Bl. with N.R. but not with C.H.B. (Case 111, see p. 84), or B.B.Bl. sometimes with C.H.B. and sometimes with

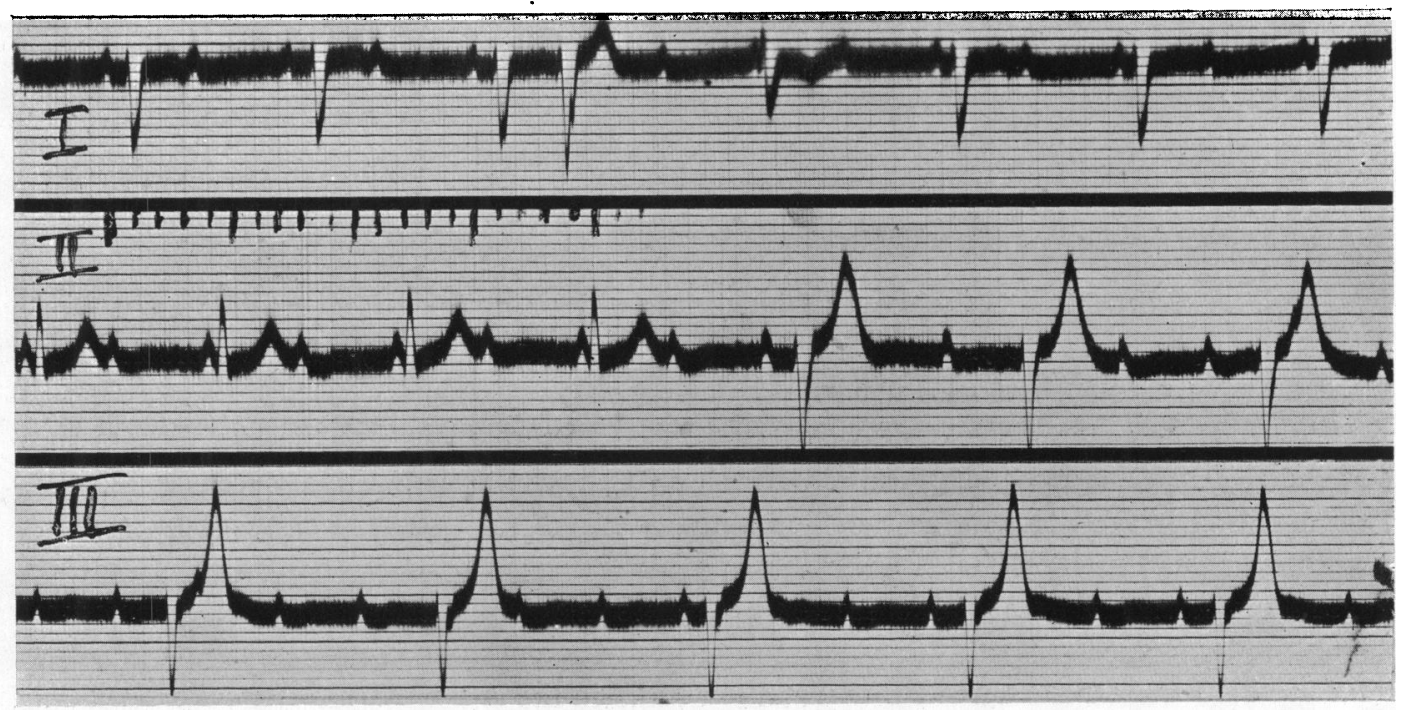

FIG. 7.-Complete and $2: 1$ heart block in a man, aged 60, in whom such changes were frequent. Here the abnormal ventricular complexes came when the block was complete, but this was not always so (Case 131). He had frequent Stokes-Adams attacks and died a year later.

N.R. (Case 102, see p. 81). Fig. 7 illustrates a change in the ventricular complexes when the degree of block changed from $2: 1$ to complete.

All the three patients with aortic stenosis and C.H.B. had B.B.Bl. also.

\section{Persistence or Change in the Degree of Block}

Complete heart block may continue from the time it is first observed until the patient's death. In many cases, however, there are frequent or occasional changes, and different grades of block are observed from time to time. The change may be only to partial block or to latent block, or even to normal rhythm with a normal P-R interval. All cases, except those with congenital complete block, have of course had normal rhythm earlier but this is not included; a few may have had latent block for some time before complete block developed, but the small numbers in whom this sequence of events was observed show that it is not common. It is not easy to classify the different combinations of these changes. This is mainly because of their variety, but partly because the patient is only under close observation for a relatively short time.

Before discussing the changes found in this series of cases the various possibilities will be set out more fully. Complete heart block may be established when that rhythm is per- 
sistent from the start. ' It may be varying, when complete, partial, or latent block follow one another from time to time. It may be varying becoming established when changes are present at first but do not persist. This is a form of progressive heart block but certain cases with a more regular increase in the degree of block have been considered as a special sub-division, progressive heart block. It may be remittent or interrupted, when partial or latent block occasionally interrupts complete block. These remissions may come after a period of years when complete block was present each time the patient was seen and had appeared to be established; in others they are more frequent and it may be difficult to draw the line between this and the varying group. All these changes are found in patients who have no StokesAdams attacks as well as those who have. In all these groups complete heart block is either the dominant or at least a common rhythm.

There are also cases where complete block is the unusual or temporary rhythm and these can be usefully divided into two groups. It may be transient, when it follows cardiac infarction or an acute infection and only lasts during this; or paroxysmal, when it occurs without such a known cause. In connection with these cases previous views about paroxysmal heart block will be shortly discussed. The present series of cases will now be considered to see how they fit into the suggested classification.

The details of the changes that were recorded are set out in Table IV. In 29 cases all records taken showed complete heart block, in 3 all showed $2: 1$ block, and in 4 both these rhythms but no other. Another $28 *$ cases showed complete and/or $2: 1$ block and at other times latent block only, 15 of these having complete block, $2 \vdots 1$ block, and latent block at different times.

TABLE IV

Grades of Heart Block

\begin{tabular}{|c|c|c|c|c|c|c|c|}
\hline & $\begin{array}{l}\text { Latent } \\
\text { block } \\
\text { (total) }\end{array}$ & $\begin{array}{c}\text { Dropped } \\
\text { beats } \\
\text { (total) }\end{array}$ & $2 \underset{\text { (total) }}{11 \mathrm{H} . \mathrm{B}}$ & $\begin{array}{l}\text { C.H.B. } \\
\text { (total) }\end{array}$ & $\begin{array}{l}\text { Stokes- } \\
\text { Adams } \\
\text { attacks }\end{array}$ & $\begin{array}{l}\text { Total } \\
\text { number } \\
\text { of cases }\end{array}$ & $\begin{array}{c}\text { Corrected } \\
\text { figures } \\
\text { using } \\
\text { clinical } \\
\text { evidence } \\
\text { also } \dagger\end{array}$ \\
\hline \multirow{8}{*}{$\begin{array}{l}\text { C.H.B. only } \\
2: 1 \text { H.B. only } \because \\
2: 1 \text { H.B. and C.H.B. } \\
\text { C.H.B. and latent block } \\
\text { C.H.B., } 2: 1 \text { H.B., and } \\
\text { latent block ... } \\
2: 1 \text { H.B. and latent } \\
\begin{array}{l}\text { Latent block with dropped } \\
\text { beats only } . .\end{array} \\
\text { Latent block only }\end{array}$} & - & - & - & 29 & 14 & \multirow{5}{*}{$\left.\begin{array}{r}29 \\
3 \\
4 \\
6 \\
15 \\
7\end{array}\right\} 36$} & \multirow{7}{*}{$\begin{array}{r}23 \\
2 \\
4 \\
13 \\
18 \\
4\end{array}$} \\
\hline & - & - & 3 & -4 & -4 & & \\
\hline & $\overline{6}$ & - & - & $\begin{array}{l}4 \\
6\end{array}$ & 4 & & \\
\hline & 15 & 6 & 15 & 15 & 6 & & \\
\hline & 7 & 3 & 7 & 20 & 5 & & \\
\hline & 29 & 29 & - & - & 2 & 29 & \\
\hline & 140 & - & - & - & 1 & 140 & \\
\hline & 197 & 38 & 29 & 53 & 36 & 233 & \\
\hline
\end{tabular}

$\dagger$ For the rest of the table the grade of heart block had always been proved by graphic records.

Established heart block. At first sight the group of 29 cases with complete heart block (C.H.B.) only might suggest that this rhythm generally persists without change. On examination, however, the proportion had to be reduced somewhat. In 8, few cardiograms were taken because the patients were not seen frequently or did not live long. In 6 , faster heart rates of about 60-70 were often observed in the ward, but as they always had C.H.B. when graphic records were taken it is not known if they changed to normal rhythm or to latent block or sometimes to $2: 1$ block. All 6 had Stokes-Adams attacks. In 5 of them the changes

* Case 58 , included in my previous paper as latent block only because this was the only rhythm proved graphically, has here been accepted as complete block also since the clinical evidence for a higher grade of block was good. 
were frequent; and 3 of these died in less than a year. In the sixth the changes were frequent for three months but in the last six months of his life the rhythm seemed always C.H.B. and he had no more Stokes-Adams attacks.

In the remaining 15 , frequent cardiograms were taken more or less regularly, and so far as we know the block was always complete at all other times as well. Of these, 8 died after 1-7 years, and 7 were alive when last heard of after 3-20 years. The classification of these cases would, therefore, be: established 15; varying 5; and varying becoming established 1.

Varying heart block. There were 4 cases with complete and $2: 1$ block. In 3 the changes were frequent but 2 were not under observation for very long; and in 1, the rhythm was generally $2: 1$ during the first few months but later became established C.H.B. for 12 years (varying, 3; varying becoming established, 1).

The 28 patients with complete, partial, and/or latent block must next be considered, and some details are given in Table V. Not all of them, however, are to be classified as varying, in spite of the three rhythms being present: nearly half (13 out of 28$)$ fell into this group and there was little to say except that the different grades of heart block were present from time to time and one had not much idea what rhythm would be found at the next visit. These changes were of all types from Case 109 (p. 84) where the only cardiogram taken showed 2: 1 block, dropped beats, and latent block in the three leads, or Case 112 who showed these three rhythms on the same day but generally had a slow heart ( $2: 1$ or complete block), to Case 107 .

Case 107. A woman, aged 42, had rheumatic mitral disease without much evidence of stenosis. Her symptoms started with a Stokes-Adams attack and after many attacks she died in one in the

TABLE V

Patients with latent Heart Block and Higher Grades

\begin{tabular}{|c|c|c|c|c|c|c|c|c|c|}
\hline \multirow{2}{*}{$\begin{array}{c}\text { Case } \\
\text { No. }\end{array}$} & \multirow{2}{*}{\multicolumn{2}{|c|}{$\begin{array}{c}\text { Sex and Age } \\
D=\text { Died } \\
\text { n.t. }=\text { not traced }\end{array}$}} & \multirow{2}{*}{ Aetiology } & \multirow{2}{*}{$\begin{array}{c}\text { Wasser- } \\
\text { mann } \\
\text { reaction }\end{array}$} & \multicolumn{2}{|c|}{ P-R interval with } & \multirow{2}{*}{$\begin{array}{l}\text { Com- } \\
\text { plete } \\
\text { heart } \\
\text { block }\end{array}$} & \multirow{2}{*}{$\begin{array}{l}\text { Stokes- } \\
\text { Adams } \\
\text { attacks }\end{array}$} & \multirow{2}{*}{$\begin{array}{c}\text { Bundle } \\
\text { branch } \\
\text { block }\end{array}$} \\
\hline & & & & & $\begin{array}{l}\text { latent } \\
\text { block }\end{array}$ & $\begin{array}{c}2: 1 \\
\text { block }\end{array}$ & & & \\
\hline 101 & m. 57 & $\mathrm{D}$ & Sy.; B.P. $250 / 130$ (see p. 83 ) & + & $0 \cdot 17$ & $0 \cdot 17$ & + & - & $\cdots$ \\
\hline 102 & m. 63-67 & D & Ath. aortic st. (see p. 81) & - & $0 \cdot 22$ & &.+ & - & B.B.BI. \\
\hline 103 & f. 66 & D & B.P. $250 / 115(\sec$ p. 81$)$ & - & $0.21 *$ & $0 \cdot 21$ & + & . & - \\
\hline 104 & m. 64-69 & & Heart $+($ W.R. +$)$ & + & $0.34 *$ & $0 \cdot 31$ & - & -- & - \\
\hline 105 & m. $67-75$ & & Heart $+($ see p. 82) & - & $0 \cdot 33$ & 0.30 & $-t$ & St.A. & - \\
\hline 106 & m. $64-65$ & & Heart failure (see p. 82) & & $0 \cdot 20$ & $0 \cdot 19$ & + & - & -- \\
\hline 107 & f. $42-47$ & D & Rh. mitral st. (see p. 80) & - & $\left\{\begin{array}{l}0 \cdot 28^{*} \\
0 \cdot 32\end{array}\right.$ & $\left.\begin{array}{l}0.24 \\
0.36\end{array}\right\}$ & + & St.A. & - \\
\hline 108 & m. $34-35$ & $\mathrm{D}$ & Sy. (see p. 81) & $(+)$ & 0.22 & $0 \cdot 22$ & + & St.A. & B.B.Bl. \\
\hline 109 & m. 52 & n.t. & Heart failure (see p. 84) & & $0 \cdot 17^{*}$ & $0 \cdot 19$ & - & - & - \\
\hline 110 & f. $62-63$ & D & Cor. atheroma & & $0 \cdot 24^{*}$ & $0 \cdot 24$ & + & St.A. & - \\
\hline 111 & m. $73-76$ & $\mathrm{D}$ & Heart $+($ see p. 84$)$ & - & $0 \cdot 28$ & - & + & St.A. & - \\
\hline 112 & f. 72 & $\mathrm{D}$ & B.P. $200 / 100$ & - & $0.29 *$ & $0 \cdot 28$ & - & - & - \\
\hline 113 & f. $29-43$ & & Rh. aortic inc. (see p. 83) & - & $0 \cdot 17 *$ & $0 \cdot 19$ & +1 & - & - \\
\hline 114 & m. 51 & n.t. & Heart $+($ see p. 81$)$ & & $0.21 \uparrow$ & - & + & - & B.B.BI. $\dagger$ \\
\hline 115 & m. 66-67 & D & Heart failure (see p. 85) & - & $0 \cdot 20$ & $0 \cdot 19$ & & St.A. & B.B.Bl. \\
\hline 116 & m. $66-67$ & $\mathrm{D}$ & Heart + & & $0 \cdot 24$ & $0 \cdot 24$ & - & St.A. & -. \\
\hline 117 & m. 56 & $\mathrm{D}$ & Heart + & & - * & $0 \cdot 26$ & - & - & - \\
\hline 118 & f. $61-64$ & & . 81) & - & $0 \cdot 24$ & - & + & St.A. & $\therefore$ \\
\hline 11 & m. $49-54$ & & Cor. ath. (Sy.) & - & $0 \cdot 44 *$ & 0.44 & + & - & -- \\
\hline 120 & m. $58-60$ & $\mathrm{D}$ & B.P. $210 / 130($ see p. 81$)$ & + & $0 \cdot 22$ & - & + & St.A. & B.B.Bl. \\
\hline 12 & m. 68 & n.t. & Cor. ath.; B.P. $210 / 90$ & - & $0 \cdot 26$ & $0 \cdot 25$ & - & St.A. & - \\
\hline 12 & m. $74-78$ & $\mathrm{D}$ & Heart + & - & $0 \cdot 22$ & - & + & St.A. & B.B.BI. \\
\hline 123 & m. 46 & D & Sy. aortic incomp. (see p. 90 ) & - & $0 \cdot 32$ & $0 \cdot 32$ & + & St.A. & - \\
\hline 12 & f. $65-67$ & & B.P. $230 / 100($ see p. 81$)$ & - & $0 \cdot 28$ & $0 \cdot 29$ & + & - & - \\
\hline 12 & f. $58-68$ & & B.P. $240 / 115$ & - & $0 \cdot 23$ & 0.42 & + & - & - \\
\hline 12 & m. $43-48$ & D & $\begin{array}{l}\text { Ath. aortic st. and inc. (see } \\
\text { p. } 81 \text { ) }\end{array}$ & - & $0 \cdot 25$ & $0 \cdot 36$ & + & St.A. & B.B.Bl. \\
\hline 127 & m. 61-62 & & Heart + (see p. 82) & & $0 \cdot 2$ & $0 \cdot 24$ & + & St.A. & - \\
\hline 58 & m. 76-79 & $\mathrm{D}$ & Heart + ; B.P. $280 / 100$ & + & $0 \cdot 36$ & & - & St.A. & - \\
\hline
\end{tabular}

* Dropped beats also at other times.

$\uparrow$ Nine years before. 
fifth year. During this time she most often had $2: 1$ heart block, but sometimes $2: 1$ changing to latent, or latent block alone, and much less often dropped beats or complete heart block.

Adding these 13 to the 8 already classified as varying makes 21 in this group. The remaining 15 of the 28 will be discussed under the following headings though not all are finally accepted in these groups: progressive heart block ( 7 cases), remittent heart block ( 5 cases), and temporary heart block ( 3 cases: 1 transient and 2 paroxysmal).

Progressive heart block ( 7 cases). Here there was some evidence that the grade of block was progressive and finally became complete. On theoretical grounds this might be expected to be more common or almost the rule, but it does not appear to be so. Possibly it may occur more often as a short transient stage when the patient is not under observation, but beyond the cases to be quoted we have no evidence of this.

Only in 3 of the 7 was the first rhythm latent heart block.

Case 114. A P-R interval of $0.21 \mathrm{sec}$. with bundle branch block was recorded in 1929 in a man, aged 42 ; in 1938 he began to have attacks of giddiness for the first time and was found to have complete heart block, still with B.B.Bl.; nothing was known about his rhythm in the 9 years between.

Case 118. A woman, aged 60, who had had angina for 2 years and a stroke 5 years before, had a P-R interval of $0.23 \mathrm{sec}$; ; year later she was found to have complete heart block which persisted for the two years she was under observation; six weeks before this she had her first real Stokes-Adams attack so probably this was the time when her block became complete.

Case 120. A man, aged 58, with high blood pressure was observed regularly for a month with a P-R interval of $0.22 \mathrm{sec}$; a year later he was seen with complete block and congestive failure from which he died eight months later; he had no Stokes-Adams attack till just before his death and there was no clinical evidence of when the change of rhythm took place.

Apart from the earlier observation of latent block these 3 might all be classed as established C.H.B. In the next two there was varying partial block as the first finding, and later one had varying and one established C.H.B. Case 108 seems a good example of progressive heart block, but he started with Stokes-Adams attacks six months before his admission to hospital, so that probably he should be classed as varying becoming established. The last should certainly be classified as varying but was interesting from the progressive change in the P-R interval when there was a A-V conduction.

Case 103. In a woman, aged 66, with high blood pressure, dropped beats without progressive lengthening (P-R interval 0.21 sec.) were recorded when she was first seen and she died five months later, her rhythm during the last few months varying between $2: 1$ and complete block.

Case 124. In a woman, aged 65 , with high blood pressure, partial block (dropped beats or sometimes $2: 1$ block) was always present during the first six months observation after which she always had complete block; her symptoms of dyspnoa and palpitation were much the same during the three years.

Case 108. A man, aged 34, always had a heart rate of about 66 and a P-R interval of 0.21 sec. for the first fourteen days in hospital. His heart rate then became slower and irregular (generally 40-48) and records showed latent and 2:1 block and a more deeply inverted T III. After six days his heart rate fell to 26-36 and apparently complete block became his usual rhythm after this. $\mathrm{He}$ was two more months in hospital and died suddenly eight months later.

Case 126. A man, aged 43, with aortic stenosis and incompetence of unproved ætiology, had complete heart block the first time he was seen, but the next time latent block and bundle branch block: and the figures in Table VI show that if the occasions with complete block were omitted there was a progressive lengthening of the P-R interval from 0.24 to $0.41 \mathrm{sec}$. during the course of three years. He died with congestive heart failure in the fourth year. There was no other case at all comparable with this.

Remittent complete heart block (C.H.B. interrupted generally by latent block ( 5 cases)).

Case 102. A man, aged 63, with atheroma and aortic stenosis was seen most months for three years and his heart rate was always between 30 and 44 (in cardiograms, C.H.B. with V. 36 to 44) except once during the first year when he had a heart rate of 76 with a P-R interval of $0.22 \mathrm{sec}$. 
TABle Vi.-Unusual Progressive Lengthening of P-R Interval

\begin{tabular}{|c|c|c|c|c|c|c|}
\hline \multirow{2}{*}{ Date } & \multirow{2}{*}{. } & \multirow{2}{*}{ Rhythm } & \multirow{2}{*}{$\begin{array}{l}\text { Bundle } \\
\text { Branch } \\
\text { Block }\end{array}$} & \multicolumn{2}{|c|}{ Heart rate } & \multirow{2}{*}{$\underset{\text { interval }}{\mathrm{P}-\mathrm{R}}$} \\
\hline & & & & Aur. & Vent. & \\
\hline $\begin{array}{c}22 / 2 / 24 \ldots \\
9 / 5 / 24 \ldots \\
6 / 6 / 24 \ldots \\
10 / 10 / 24 \\
13 / 3 / 25 \ldots \\
5 / 6 / 25 \ldots \\
23 / 10 / 25 \\
12 / 2 / 26 \ldots \\
11 / 3 / 27 \ldots \\
27 / 9 / 27 \ldots \\
15 / 6 / 28 \ldots\end{array}$ & $\begin{array}{l}\ldots \\
\cdots \\
\cdots \\
\cdots \\
\cdots \\
\cdots \\
\cdots \\
\cdots \\
\cdots\end{array}$ & $\begin{array}{l}\text { C.H.B. } \\
\text { Latent B. } \\
\text { Latent B. } \\
2: 1 \mathrm{~B} . \\
2 \vdots 1 \mathrm{~B} . \\
2 \vdots 1 \mathrm{~B} . \\
\text { C.H.B. } \\
2: 1 \mathrm{~B} . \\
\text { C.H.B. } \\
\text { (C.H.B.) } \\
\text { C.H.B. }\end{array}$ & $\begin{array}{c}\text { B.B.Bl. } \\
\mathbf{N} \\
\mathbf{N} \\
\mathbf{N} \\
\mathbf{N} \\
\mathbf{N} \\
\text { B.B.Bl. } \\
\mathbf{N} \\
\text { B.B.Bl. } \\
\text { B.B.Bl. } \\
\text { B.B.Bl. }\end{array}$ & $\begin{array}{c}100 \\
66 \\
50-60 \\
76 \\
86 \\
76 \\
86 \\
80 \\
110 \\
76-81 \\
62\end{array}$ & $\begin{array}{c}48 \\
66 \\
50-60 \\
38 \\
43 \\
38 \\
39 \\
40 \\
55 \\
38 \\
42\end{array}$ & $\begin{array}{l}\overline{0} \\
0 \cdot 24 \\
0 \cdot 26 \\
0 \cdot 32 \\
0 \cdot 32 \\
0 \cdot 35 \\
\overline{-} \\
0 \cdot 41 \\
\overline{(0 \cdot 48)^{*}} \\
-\end{array}$ \\
\hline
\end{tabular}

* Some of this was certainly C.H.B.: some looked like $2: 1$ block with a P-R interval of 0.48 sec., but it might have been chance with the auricular almost exactly twice the ventricular rate.

Case 125. This woman of 58 with high blood pressure was seen regularly for eleven years and always had complete block at each visit, except once in the sixth year when she was seen with normal rhythm at a rate of 60 (to 78) with a P-R interval of $0.23 \mathrm{sec}$. (Fig. 8), and once in the seventh year when she had a record of $2: 1$ and $3: 1$ block (P-R, $0 \cdot 40$ and 0.26 sec. respectively).

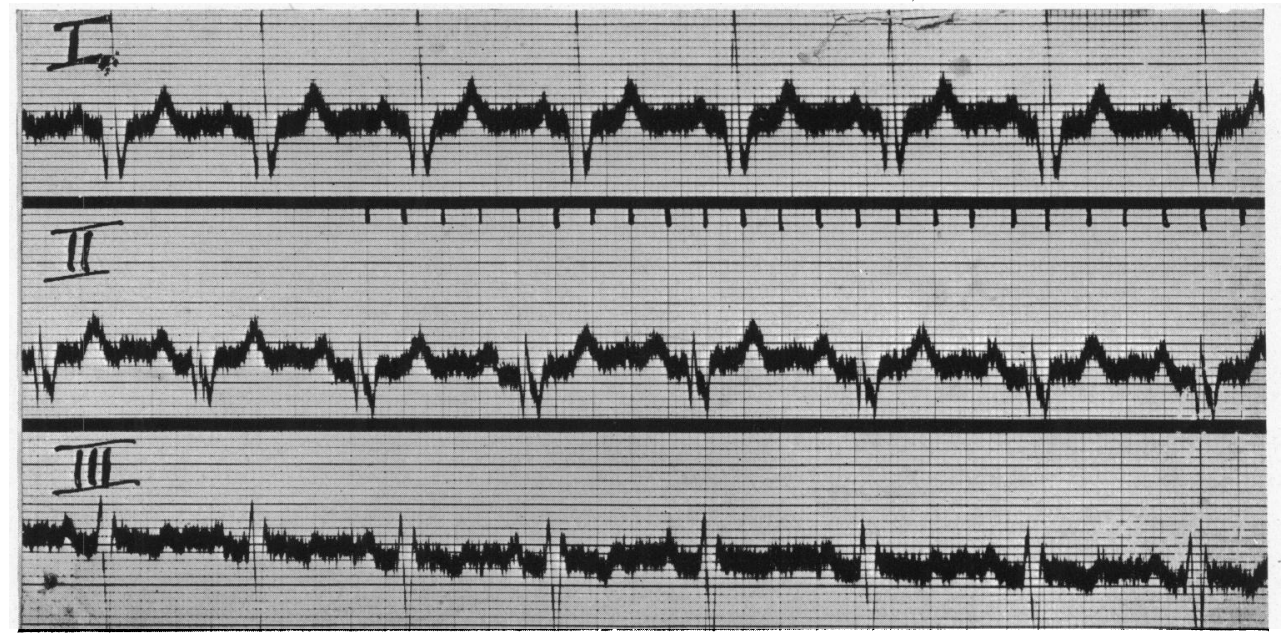

FIG. 8.-Sinus rhythm with latent block, $P-R \quad 0.23$ sec., interrupting complete heart block that had been established for six years (Case 125).

Case 106. This man of 64 attended regularly for a year and always had complete block except once when latent and $2: 1$ block were both observed.

Case 127. This man of 61 was seen regularly for about 18 months and generally had $2: 1$ or complete block, but on two occasions his heart rate changed from about 40-44 to 60-78 when he had normal rhythm with a P-R interval of $0.24 \mathrm{sec}$.

Case 105. The last case was less striking, and might have been included on varying. A man, aged 64, always had complete heart block when in hospital in 1931. In 1934, when followed up, he was seen with $2: 1$ block (rate 32; P-R 0.30 sec.) and with latent block (rate 52; P-R 0.33 sec.). In 1939, when he was in hospital again with carcinoma of the penis, he had complete block.

Dividing up the progressive group, where the cases could generally be classified in one of the larger groups, and omitting those where the period of observation was only short, the distribution was as follows:

$\begin{array}{lllllllr}\text { Established heart block } & \ldots & \ldots & \ldots & \ldots & \ldots & \ldots & 18 \text { cases } \\ \text { Remittent heart block } & \ldots & \ldots & \ldots & \ldots & \ldots & 5 \text { cases } \\ \text { Varying, latent, or partial, becoming established } & \ldots & \ldots & 7 \text { cases } \\ \text { Varying heart block } & \begin{array}{llll}\text { Vary } \\ \text { Paroxysmal and transient block }\end{array} & \ldots & \ldots & \ldots & \ldots & 23 \text { cases } \\ \text { Paroxy }\end{array}$




\section{Paroxysmal Heart Block}

Before discussing paroxysmal heart block, previous papers on the subject will be considered very shortly. After the case of Hay (1906) with $2: 1$ heart block and a normal a-c interval, Gossage (1909) described a case with intermittent complete block and a normal P-R interval at other times. In the well-known case of Starling (1921) Stokes-Adams attacks could be induced by swallowing though the $\mathrm{P}-\mathrm{R}$ intervals were normal, but later complete heart blocks became established. Carter and Dieuaide (1923) collected 8 such cases and added one of theirs where there were repititive Stokes-Adams attacks with complete block just after, and a normal conduction time between the attacks: they called it recurrent or intermittent heart block.

Comeau (1937) accepted 12 of 20 possible reported cases as proved examples of paroxysmal heart block and added 1 of his own; most had Stokes-Adams attacks but it was not an essential feature. The same year Gilchrist (1937) said he had seen 8 cases where the sequence of events was normal rhythm, Stoke-Adams attack, complete heart block (for minutes or hours), and then again normal rhythm with a normal P-R interval; he gave details of 2 of the cases, one proved electrocardiographically, and the other by a heart rate of 35 and improvement with ephedrine. Paul White (1937) speaks of cases of heart block as temporary and functional or permanent and organic, but this does not seem to be a sufficient division. Other cases have been mentioned in the paper of Laurence and Forbes (1944). The terms paroxysmal, intermittent, and recurrent have been used indiscriminately for this condition. The former seems the most suitable term for this clinical picture, partly because it is already used for paroxysmal tachycardia and paroxysmal auricular fibrillation.

It has generally been limited to cases where the $\mathbf{P}-\mathbf{R}$ interval was normal in between, but this prevents such a diagnosis being made precisely in many cases when no graphic record can be obtained of the usual rhythm with a normal heart rate. I suggest that paroxysmal heart block should be used as a clinical term when a normal heart rate with or without latent block is the usual rhythm and heart block the occasional finding. The two groups could be distinguished as paroxysmal heart block (complete) when the $\mathrm{P}-\mathrm{R}$ interval is normal in the interval, and paroxysmal complete heart block, when there is latent block in the interval. This distinction is of practical importance, for the diagnosis of some Stokes-Adams attacks will be missed unless the existence of paroxysmal heart block (complete) is more widely recognized, because the normal $\mathrm{P}-\mathrm{R}$ interval found in between will lead to the false assumption that the syncopal or epileptiform attack can not have been of the Stokes-Adams type. Dr. Suzman's case at the end of the appendix is a good illustration of this difficulty.

The term transient heart block could be used when there is a known temporary cause, such as infection or immediately after cardiac infarction.

Transient heart block. One patient fell into this group, as she had temporary block due to an acute infection.

Case 113. A woman, aged 28, already had aortic incompetence and in her third attack of rheumatic fever developed complete block which lasted for a week and was followed by partial block, sometimes with dropped beats and sometimes $2: 1$, this persisting for three months. Full details have been published (Campbell, 1931). In spite of this she made an excellent recovery and is still in good health 14 years later with a normal P-R interval. In this time there has been very little change, and she is able to do a fair amount of work running her father's house.

Paroxysmal heart block. Two patients were included in this group without any doubt.

Case 101. A man, aged 57, with a blood pressure of 250/130 was in hospital with symptoms suggestive of neuro-syphilis and a stroke four years before. He was found with complete heart block which changed sometimes to $2: 1$ and sometimes to occasional ventricular responses with a P-R interval of $0.17 \mathrm{sec}$. After two weeks the block disappeared and for the rest of the time in hospital he had normal rhythm with the same length of $P-R$ interval. He had a large heart, a strongly positive Wassermann reaction, and mental symptoms suggestive of general paralysis, and unfortunately he was lost sight of as it was necessary for him to be transferred to a mental hospital. 
Case 111. A man, aged 73, with high blood pressure, was admitted with Stokes-Adams attacks. He was found to have complete heart block which persisted for four weeks. It then changed to sinus rhythm with bundle branch block and a P-R interval of 0.27 sec., and this persisted for the next month in hospital, and was still present when he was seen a year later. Such an occurrence is, of course, not uncommon where complete block occurs temporarily after a coronary thrombosis, but there was no evidence of this in his case.

With the classification proposed this would be paroxysmal complete heart block, as latent block was present when he had sinus rhythm, and Case 101 and Dr. Suzman's case in the appendix would be paroxysmal heart block (complete).

There are four other cases that must be considered shortly here as they all had heart block ( 3 with complete and 1 with 2:1 heart block) and at other times sinus rhythum with a P-R interval that was nearly or quite normal.

Case 106 (p. 82) has been described as remittent because complete block was always found except once when he had $2: 1$ block (P-R, 0.19 sec.) and latent block (P-R, 0.20 sec.).

Case 115. This man, aged 66, was included as varying heart block because there were frequent proved changes of $2: 1(\mathrm{P}-\mathrm{R}, 0 \cdot 19)$ and latent block ( $\mathrm{P}-\mathrm{R}, 0.20 \mathrm{sec}$.) and presumed complete block as he started with a Stokes-Adams attack and had several others.

Case 109. This man, of 52, was also included as varying, since $2: 1$ and dropped beats and latent block with a P-R interval of $0.17 \mathrm{sec}$. were all observed in quick succession: his after history is unfortunately not known and his heart failure may have been due to an acute infection or to infective endocarditis.

Finally Case 103 was included as progressive (partial to varying), but if a $P-R$ interval of $0 \cdot 21$ sec. in an elderly woman may be regarded as normal she could also be regarded as paroxysmal heart block in the sense in which this has generally been used. These last two patients were included by Laurence (1944) being quoted from Table III of an earlier paper (Campbell, 1943b).

\section{$2: 1$ HEART BLOCK}

This is a much less stable rhythm than complete heart block. It must be very rare for it to persist without changes for long periods, though in a few patients it seems the dominant rhythm for some time, occasionally even for years. There were 4 cases with $2: 1$ and complete heart block. In 2 of these frequent changes were observed during the 2 and 5 years respectively that they lived. In the third the block was always, I think, $2: 1$ during the month he was in hospital except once when the rare $3: 1$ rhythm was observed, probably due to atropine. Soon after it became complete and so far as I know this continued for the remaining 12 years of his life, except once in the second year when $2: 1$ block was again recorded (Case 142, see appendix). The fourth has been traced recently after six years (Case 143).

Case 143. A man, aged 38, became short of breath rather suddenly and had at first some minor Stokes-Adams attacks. When seen recently and at the first visit $2: 1,3: 1$, and complete block were all recorded: he was quite familiar with the change, which took place frequently, but it seemed that $2: 1$ had remained his predominant rhythm during all the period and that the other rhythms were only present for a short part of the time.

Of the 3 cases where only $2: 1$ block was recorded, none had cardiograms frequently, but in 2 this rhythm seemed persistent and in 1 a heart rate of 70 was observed clinically during the four to six weeks in hospital.

There were also 7 cases where $2: 1$ and latent block were the only rhythms recorded, but in at least 3 of these there was good clinical evidence of complete block and as 5 of the 7 had Stokes-Adams attacks it was probably present in more than this.

$3: 1$ heart block. This is a much less common rhythm and I have never seen it persist. It is seen most often as a change from $2: 1$ heart block as in Fig. 9.

The $P-R$ interval in $2: 1$ heart block. This should have been dealt with in the paper on partial heart block (Campbell, 1943b), but was only referred to incidentally when patients had this rhythm and dropped beats as well. It was generally of about the same length as the 


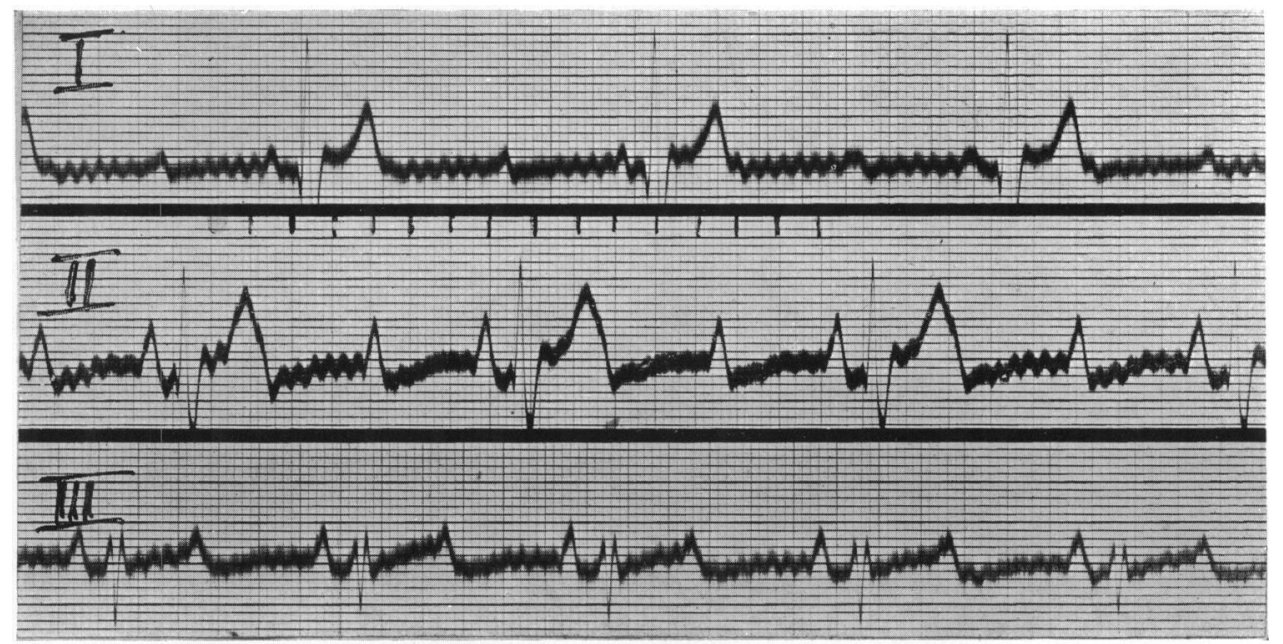

FIG. 9.-3 : 1 heart block in a man who at that time generally had $2: 1$ heart block (as in lead III) and for twelve years afterwards had complete heart block (Case 142). There was little if any change in the P-R interval, which was about $0 \cdot 21 \mathrm{sec}$.

first P-R interval with a response. There were 29 cases with records of $2: 1$ block and the $\mathrm{P}-\mathrm{R}$ intervals were as follows:

Less than 0.20 secs., 8 cases; $0 \cdot 21-0.22$ sec., 4 cases; $0 \cdot 23-0.24$ sec., 5 cases; $0 \cdot 25-0.26 \mathrm{sec}$., 2 cases; $0 \cdot 27-0.32$ sec., 7 cases; $0 \cdot 36,0.40$, and 0.42 sec., 3 cases.

I was surprised that in nearly one third of the cases the P-R interval was normal and sometimes as short as $0.16 \mathrm{sec}$. In 3 of the 7 cases where $2: 1$ block was the only rhythm observed the P-R interval was normal and only in 2 of the 7 was it over $0.24 \mathrm{sec}$. The average for all the cases was $0.254 \mathrm{sec}$. This is identical with figure found for the P-R interval with latent block in cases that had $2: 1$ or complete block also (Campbell, 1943c, Table IV). The spread was rather wider as shown by the quantities, 0.19 and 0.30 sec. against 0.215 and 0.270 sec. The fact that the increase in the $P-R$ interval is small or absent in so many cases of $2: 1$ heart block shows again that a defect of excitability or some other factor as well as a defect of conductivity is needed to explain the observed facts.

\section{Prognosis}

Two thirds of the cases have died and one third were still alive when last seen after an average period of 6 years. Of the 64 cases, 14 were under observation for a short period only, so have been omitted, leaving 50 for consideration. Of these, 34 died, 10 in less than a year, 9 in the second year, 14 in from 2-6 years, and 1 (Case 142, appendix) after 12 years. The average period of survival was $2 \cdot 5$ years.

Of the 16 who were still alive, 2 were under observation for more than one but less than two years, 8 for from 2-6 years, and 6 for 7, 7, 8, 11, 14, and 20 years respectively. The average period of survival was 6 years. Possibly the last two (Cases 113 and 140, see appendix) should be omitted as the first had transient block during acute rheumatism and the second may have had congenital block though this was not the diagnosis made at the time: if so, the average period would be reduced to 4.4 years. These results are shown in Table VII.

TABLE VII

\begin{tabular}{|c|c|c|c|c|c|c|c|c|}
\hline \multirow[b]{2}{*}{ Length of period } & LENGTH OF LIFE & \multicolumn{5}{|c|}{ after Observation of Heart Block } & \multirow[b]{2}{*}{$\begin{array}{c}6-9 \\
\text { years }\end{array}$} & \multirow[b]{2}{*}{$\begin{array}{l}10 \text { years } \\
\text { or more }\end{array}$} \\
\hline & $\begin{array}{l}\text { Less than } \\
1 \text { year }\end{array}$ & $\begin{array}{c}1-2 \\
\text { years }\end{array}$ & $\begin{array}{c}2-3 \\
\text { years }\end{array}$ & $\begin{array}{c}3-4 \\
\text { years }\end{array}$ & $\begin{array}{l}4-5 \\
\text { years }\end{array}$ & $\begin{array}{c}5-6 \\
\text { years }\end{array}$ & & \\
\hline $\begin{array}{l}\text { No. of patients who have died } \\
\text { No. of patients who are alive }\end{array}$ & $\begin{array}{r}10 \\
0\end{array}$ & $\begin{array}{l}9 \\
2\end{array}$ & $\begin{array}{l}3 \\
3\end{array}$ & $\begin{array}{l}4 \\
3\end{array}$ & $\begin{array}{l}3 \\
1\end{array}$ & $\begin{array}{l}4 \\
1\end{array}$ & $\begin{array}{l}\mathbf{0} \\
\mathbf{3}\end{array}$ & $\begin{array}{l}1 \\
3\end{array}$ \\
\hline
\end{tabular}


The figures agree surprisingly. closely with those of Graybiel and White (1936), which suggests that the series are large enough to give an accurate picture. They found that 49 patients had died after an average period of under 3 years, and that 17 were alive after an average period of just under 7 years.

As a contrast the average duration of life in my 10 congenital cases is 22 years, and 7 of the 10 are known to be still living.

From such figures one can calculate the expectation of life if one assumes that surviving patients continue to die at the same rate as those who have died already-probably a pessimistic assumption. If $x$ per cent are alive after an average period of $b$ years, and $100-x$ per cent have died after an average period of $a$ years, $100-x^{2} / 100$ will have died after $2 a$ years and $\frac{100 a-a x+\left(x-x^{2} / 100\right)(a+b)}{100-x^{2} / 100}$ will be an approximation to the average duration of life for all cases.

This gives 4.6 years as the expectation of life for complete heart block calculated from my figures and 4.5 years from those of Paul White and Graybiel (1936). The prognosis is better than that for bundle branch block, 3 years, but worse than that for a recent cardiac infarct (excluding deaths in the first six weeks) where it was 6.5 years, these figures having been calculated in the same way from my own cases.

Changes of rhythm did not seem to affect the prognosis unless these were associated with Stokes-Adams attacks. Thus there was no difference as regards prognosis between those having complete heart block with latent block and those having complete heart block without latent block. If Stokes-Adams attacks are more frequent with changes in the degree of block, a worse prognosis might have been expected. The apparent anomaly might be because there were some cases without proved latent block who had nevertheless changes of rhythm of other types or changes observed clinically but not recorded. The 11 cases of this type were, therefore, transferred and the two groups were analysed again as regards prognosis. But there was still no great difference (see later).

Undoubtedly the prognosis was specially bad in the group with frequent changes of rhythm and Stokes-Adams attacks when they were first seen, but this happened to be balanced by the man who lived 12 years with Stokes-Adams attacks, although at first he had frequent changes of rhythm, and by other similar cases.

There were 36 cases having heart block without latent block; 25 of these were under observation for a reasonably long period. Eighteen of these died and 7 were still alive when last heard of. Ten died in less than 2 years; 7 in from 2-6 years; and 1 after 12 years; the average period of survival being 2.7 years. Of the 7 who were still alive, 4 were under observation for from 2-6 years, and 3 for 7 , 7 , and 20 years respectively; the average period was 4.5 years or 7 years if the last exceptional case was included.

There were 28 cases having heart block with latent block; 25 of these were under observation for a reasonably long period. Sixteen of these died and 9 were still alive when last heard of. Nine died in less than 2 years and 7 in from 2-6 years, the average period of survival being $2 \cdot 3$ years; this was a little shorter than in the group without latent block but the difference was not significant. Of the 9 who were still alive, 2 were under observation for more than 1 year, 4 for from 2-6 years, and 3 for 8,11 , and 14 years respectively; the average period was just over 6 years, or 4.3 years if the last case be excluded. Again the period was a little shorter but the difference was not significant.

If the patients were divided into two groups-those known to have different grades of heart block and those only known to have complete block-by the transfer of the 11 cases referred to, the difference between the two groups were still slight.

There were 25 cases without change of rhythm, 8 of whom were not traced: 11 died ( 5 in less than 2 years, and 6 in from 2-6 years), the average period of survival being 2.5 years; and 6 were still alive (4 after 2-6 years, 1 after 7 years, and 1 after 20 years), the average period being 7.0 years, or 4.3 years if the last case be excluded.

There were 39 cases with change of rhythm, 6 of whom were not traced: 23 died (14 in less than 2 years, 8 in 2-6 years, and 1 in 12 years), the average period of survival being 2.7 years (2.3 years without the last case); 10 were still alive ( 2 after 1 year, 4 after 2-6 years, and 4 after 7, 8, 11, and 14 years), the average period being 4.4 years, or 5.4 years if the last case be excluded. 
Incidence of Stokes-Adams Attacks

Just over half the patients with complete and/or $2: 1$ heart block had Stokes-Adams attacks-33 out of 64 . Originally, as the relationship with latent block was being specially investigated, they were divided into two groups-those with and those without recorded latent block-and rather surprisingly in view of the reputed association of Stokes-Adams attacks with a changing degree of block there was no significant difference in the incidence of Stokes-Adams attacks (53 against 50 per cent). But there is no great danger in the change from latent block to dropped beats or to $2: 1$ block when no new centre has to take control, and it is only the change from one or other of these rhythms to idiopathic ventricular rhythm that is attended by the risk of a Stokes-Adams attack.

Among the group without recorded latent block there were 4 with $2: 1$ block, and 7 with faster rates that did not chance to be graphically recorded. Here the incidence of StokesAdams attacks were specially high, 10 of these 11 cases, possibly because they were in hospital for their Stokes-Adams attacks just at a time when these were most frequent owing to the frequent changes of rhythm. If these 11 cases were moved, 25 of the 39 with known change of rhythm had Stokes-Adams attacks (64 per cent), and only 8 of the 25 with no known change from their complete heart block ( 32 per cent). This is not meant to imply that even in these last there was not a change of rhythm at the time of their Stokes-Adams attacks, but that no such changes were noted at other times when they were under observation, and that the precise behaviour of the heart with their attacks was not known. There were several cases where Stokes-Adams attacks were more frequent at or near the start and the patient " grew out" of them. This may be partly due to the habituation to the slow ventricular rate and to the ventricle having become accustomed to its responsibility for initiating and maintaining the heart beat. For example, Case 136 had two Stokes-Adams attacks when 66; when 68 he was in hospital and though during the first two weeks his heart rate varied between 40 and 72 he had no more than attacks of faintness; there was little change when he was 70 and he had had no real Stokes-Adams attacks since the first two. Case 143 (p. 84) gave a very similar history. Case 145 had frequent attacks all through the day for ten days at the start when he was 62; he lived 6 years after this and the attacks were not very frequent though they continued. In Case 147 the first attack was the only typical one, though he had attacks of faintness when things went black for the remaining nine months of his life.

\section{Prognosis with Stokes-Adams Attacks}

As some of the cases were not traced there were 50 available for assessing the prognosis. It was considerably worse when there were Stokes-Adams attacks, 80 per cent of these patients having died against 50 per cent of those without such attacks.

TABLE VIII

\begin{tabular}{|c|c|c|c|c|}
\hline \multicolumn{5}{|c|}{ Stokes-Adams Attacks and Prognosis } \\
\hline & Total & Alive when last heard of & Dead & Not traced \\
\hline with Stoke-Ac & 33 & 6 & 24 & 3 \\
\hline Patients without Stoke-Adams attacks & 31 & 10 & 10 & 11 \\
\hline
\end{tabular}

Unfortunately there were far more who were not traced among the patients without such attacks, and if all these were included the percentage figures were:

With Stokes-Adams attacks $\quad \ldots \quad \ldots \quad$ Known to be alive, 19 per cent; dead, 73 per cent. Without Stokes-Adams attacks $\quad . \quad \quad \ldots \quad$ Known to be alive, 33 per cent; dead, 33 per cent.

Although more of the patients had died while under observation the length of time before death was not significantly different, the average for both groups being between 2 and $2 \cdot 5$ years. This apparent anomaly is explained by the fact that there are more of the patients without Stokes-Adams attacks still surviving, who will later increase the average duration of life considerably. 
There was no noticeable difference in any of these findings between the patients who had and those who had not latent heart block. All the figures have therefore been combined.

Method of dying. The great danger of sudden death in patients with Stokes-Adams attacks has of course been emphasized for a long time. This was again confirmed in the present series, but I was surprised to find that there was only one record of sudden death in the patients with complete heart block where a history of Stokes-Adams attacks had not been noted. No doubt patients with or without previous heart block may sometimes die in their first Stokes-Adams attacks and so come under the notice of the pathologist rather than of the clinician, but in this series only one patient seen with heart block without any evidence of Stokes-Adams attacks is known to have died suddenly. There were a few without StokesAdams attacks when first seen who developed this later and so lost their immunity from sudden death, but even so the point seems of considerable value for prognosis.

Of the 24 patients with Stokes-Adams attacks who died, no less than 14 died suddenly (almost certainly in attacks), 3 died with heart failure, and in 7 the method of death was not known.

Of the 10 patients without Stokes-Adams attacks known to be dead, 1 died suddenly, 3 had congestive heart failure, 1 left ventricular failure, 1 broncho-pneumonia, 1 cerebral hæmorrhage, 1 intestinal obstruction, and in 2 the method of death was not known.

One practical and valuable conclusion from these facts is that the patient who has not had a Stokes-Adams attack in the first month or so of his heart block is not very likely to develop such attacks, and the longer the time that passes without them, the more certain one can be that there is small risk of his dying suddenly.

\section{SUMmARY AND CONCLUSIONS}

Complete heart block is most often seen in men in the seventh decade with enlarged hearts and atherosclerosis but no other evidence of gross heart disease. Four-fifths of our patients were men. Most (45 per cent) were between 60 and 69, and 84 per cent were over 50 years of age at the onset of complete block.

Syphilitic and rheumatic heart disease were between them responsible for only just over 10 per cent of the cases. Other myocardial disease was responsible in 75 per cent, or in 86 per cent if the group of congenital cases was excluded, this being the second commonest cause (13 per cent). Cardiac enlargement with no other signs than atherosclerosis of the aorta and often of peripheral arteries was the evidence of myocardial disease in nearly half these cases, high blood pressure, angina pectoris, or congestive failure being present in the other half. In the 10 cases with high blood pressure the average figure was $225 / 108$. In the others the systolic pressure was above and below 160 in equal numbers and the average figures for these two groups were $194 / 81$ and $137 / 73$. Thus, in the latter the pulse pressure was only slightly raised, but in the former and in those with high blood pressure, the pulse pressure averaged 115. The reasons for this have been discussed.

The heart rate was usually between 28 and 40 and averaged just under 35 (excluding congenital cases where it was generally 40-56).

Heart block may be of very varied types: it may be (1) complete; (2) partial; $2: 1$, or more rarely $3: 1$ or $4: 1$; (3) partial with dropped beats only; including regular $4: 3,3: 2$, etc. or occasional dropped beats; or (4) latent, with a prolonged P-R interval only.

In addition to this there may be various changes and combinations which can be usefully described as follows. Complete heart block may be established, or varying, changing to other degrees of block, or interrupted. It may also be transient, due to a known infection or to a specific episode such as cardiac infarction, or paroxysmal, of which there are two varieties, paroxysmal complete heart block when the usual rhythm is latent heart block, and paroxysmal heart block (complete), when the usual rhythm shows a normal $\mathrm{P}-\mathrm{R}$ interval. These varieties and combinations have been discussed. 
Prognosis. Complete heart block is a serious lesion, though some patients, especially some of those under 40, live for many years in reasonably good health. There were 50 cases followed for more than 2 years or until their death; 34 were dead after an average period of 2.5 years; 16 were alive after an average period of 6 years or 4.5 years if two exceptional cases were excluded. Of the former, 19 died in less than 2 years, 14 in from 2-6 years, and 1 after 12 years. Of the latter, the period of observation was from 2-6 years in 10, and from 7-20 years in the other 6 cases.

Stokes-Adams attacks. These were present in half the patients with complete heart block. When they were present they were one of the earliest if not the first significant symptom of heart block in three-quarters of the cases. In those without Stokes-Adams attacks, dyspnœa or attacks of faintness or dizziness were the main presenting symptoms.

Stokes-Adams attacks were no more common in those who had recorded latent heart block than in those without. A known change of rhythm at times other than those of the attack does make Stokes-Adams more likely but not as much as might be expected (64 against 32 per cent).

The prognosis was considerably worse in those with Stokes-Adams attacks, the results in the patients traced being:

$\begin{array}{lllcc} & & & \text { Alive } & \text { Dead } \\ \text { With Stokes-Adams attacks } & \ldots & \ldots & 6 & 24 \\ \text { Without Stokes-Adams attacks } & \ldots & \ldots & 10 & 10\end{array}$

The method of dying was even more strikingly different: of the patients with Stokes-Adams attacks, 61 per cent died suddenly, presumably in attacks; of those without Stokes-Adams attacks, only one was known to have died suddenly and 50 per cent died with failure. If when a patient is first seen with complete heart block he has not had a Stokes-Adams attack, the risk of such an attack developing or of his dying suddenly is not great, and with each month that has passed the risk becomes still less.

It is important to realize that Stokes-Adams attacks may occur with paroxysmal heart blocks (complete) and the paroxysms may be of short duration after the attacks and may easily be missed. Otherwise attacks that are true Stokes-Adams attacks will remain unexplained.

I should like to express my thanks again to my colleagues at Guy's Hospital and at the National Hospital for Diseases of the Heart, and especially to Dr. S. Suzman, my clinical assistant, and Mr. F. H. Muir, technician to the Cardiographic Dept., Guy's Hospital, for helping me to keep in touch with so many of these patients.

\section{REFERENCES}

Campbell, M. (1931). Lancet, 2, 180.

(1943, a). Brit. Heart J., 5, 15.

- $(1943$, b). Ibid., 5, 55.

- $(1943, c)$. Ibid., 5, 163.

Carter, E. P., and Dieuaide, F. R. (1923). John Hopkins Hosp. Bull., 34, 401.

Comeau, W. J. (1937). Amer. J. med. Sci., 194, 43.

Duras, P. F. (1944). Brit. Heart J., 6,

Gilchrist, A. R. (1937). Brit. med. J., 1, 203.

Gossage, A. M. (1909). Heart, 1, 283.

Graybiel, A., and White, P. D. (1936). Amer. J. med. Sci., 192, 334.

Hay, J. (1906). Lancet, 1, 139.

Lawrence, J. S., and Forbes, G. W. (1944). Brit. Heart J., 6,

Parkinson, J., Papp, C., and Evans, W. (1941). Ibid., 3, 171.

Starling, H. J. (1921). Heart, 8, 31 .

Stern, V. S. (1944). Brit. Heart J., 6, 66.

White, P. D. (1937). Heart Disease, 2nd ed., p. 673. 


\section{APPENDIX OF CASE Notes}

\section{An Unusual Case of Stokes-Adams Attacks and Paroxysmal Heart Block}

Case 123. K. R. had malaria, dysentery, and gonorrhœa in Rhodesia; the last was treated very inadequately and was followed by crippling arthritis. Soon after he began to have attacks of vomiting with blood in the vomit and 7 years later, as this persisted, Sir Arthur Hurst diagnosed gastritis polyposa and arranged for gastrectomy (Hurst, A. F., and Stokes, A. (1926), Guy's Hosp. Rept., 76, 351). So far no mention has been made of his heart but section of some of the larger vessels of the stomach showed arteriosclerotic changes.

In 1923 , when he was 34 , he had his first syncopal attack and only remembered finding himself on the ground surrounded by servants. In 1927-8 he had 2 or 3 more attacks and in 1929 when on leave had 4 attacks in four months. Nearly all occurred when he was standing and drinking whisky. They were preceded by a momentary feeling of nausea and sometimes, if he was sitting, he had this feeling without any after developments. He never hurt himself in falling and thought he was out for up to a minute. Afterwards he felt unsteady and sometimes vomited a little bile but recovered quickly and could take another drink without effect.

In 1929-34 he had 7 or 8 more attacks. In 1935 he was readmitted to Guy's Hospital for severe arthritis of his spine and large joints. His heart rate was slow, due to varying heart block, most often $2: 1$, sometimes complete or latent. The heart was just enlarged and there was an aortic diastolic murmur. The W.R. was negative. He had no more attacks in hospital but died six months later.

Here, no precise diagnosis of the cause of the syncopal attacks were possible until some years later he developed varying heart block: it is still only a reasonable deduction that they were StokesAdams attacks and that he had paroxysmal heart block; it seems that drinking spirits may have been a special provoking cause as swallowing was in the case of Starling (1921).

\section{C.H.B. of Doubtful Actiology: Good Health after 20 Years}

Case 140. K. H. had her first and only attack of fainting when she was 19, and C.H.B. was diagnosed then. She was seen by me 12 years later, complaining of no more than some breathlessness and giddiness, and she remained under regular observation for 8 years more.

Her heart was considerably enlarged to the left with an apical systolic murmur; her B.P. remained about 180-200/80-90; her W.R. was negative; and there was no evidence of valvular disease. Her heart rate was early always between 30 and 40 and the only other cardiographic abnormality was left ventricular preponderance which remained unchanged. She continue in good health able to do light house work. It has not been possible to trace her as the area where she was last living has been bombed.

She was classified as a rheumatic case because of a history of doubtful rheumatic fever when she was 10 but there was no clinical or radiological evidence of mitral stenosis. On reviewing her case I feel it much more probable that this was a case of congenital heart block that I failed to recognize, even in my recent paper (Campbell, 1943, $a$ ).

\section{Unusual Length of Life with Stokes-Adams Attacks}

Case 142. J. H., a seaman, had no history of rheumatic fever or syphilis, and his W.R. was negative. He always had good health and served in the war 1914-18 without any complaints. In 1919, when 43, he began having attacks in which he went unconscious and fell. At first they were preceded by precordial pain which spread up the left side to the angle of the jaw and this seems to have been most severe with the first attack. His only other symptom was dyspnœea, but he had to give up work because of the frequency of the attacks-at least one a month.

In 1927 Dr. L. Forman wrote to me as follows: " This man was admitted to hospital as an epileptic. During an observed attack he became very pale and his pulse could not be obtained; later it became regular at 20 a minute; and has since been about 45." He was admitted under my care and was found to have $2: 1$ heart block $(\mathrm{V}, 40-48)$. His heart was slightly enlarged and his arteries extremely thickened. During a month in hospital he had no attacks. All records showed $2: 1$ block, even when his auricle was quickened to 120 with exercise, except once when he had been given I.A.H. 1/150 grain 4 hourly, enough to produce dryness of the mouth; he then showed $3: 1$ heart block (Fig. 9). Records of his B.P. varied, e.g. 160/90, 180/90, 170/110. A year later he came up with a pulse of 32 due to C.H.B.; his B.P. was $230 / 120$. With these two exceptions there was no change in his condition. The following months he again had 2:1 block after which every record for the next 10 years showed complete block.

He was last seen in 1938 and had been frequently an out-patient and three times in hospital. His attacks had continued unchanged though no others were observed. His description of the attacks was very much the same as at the start, but the pain became a more permanent feature again: it has an even more typical anginal spread but he had no regular angina of effort. In his later years the B.P. was generally about $240 / 90$. In some of his more severe attacks he bit his tongue and passed water-episodes which are stated not to occur in Stokes-Adams attacks, but it seems unlikely that this was a case of complete heart block developing in an epileptic and $I$ have a direct observation by a competent observer confirming the absence of the pulse during an attack. 
He died suddenly in his sleep in 1939, 20 years after the first attack and 12 years after he came under observation with heart block.

\section{C.H.B. of Unknown Actiology with Relatively Fast Ventricular Rate}

Case 159. W. W. complained of nothing till she had three or four fainting attacks when she was 18. Her doctor told her her heart was slow and sent her to hospital when complete heart block with a rate of $40-48$ was confirmed. Her heart was a little enlarged with a systolic murmur; nothing else abnormal was found; B.P. 135/70. Her slight dyspnœa improved with symptomatic treatment; her fainting attacks did not recur, and she was working and leading a normal life six years later.

The diagnosis of congenital C.H.B. was excluded because when she had scarlet fever at the age of 11 , the three recorded pulse rates were 100,70 , and 90 , and there had been no comment on her heart then or when she had pneumonia as a child. She had no family or personal history of rheumatic fever and I did not think she had mitral stenosis though this was difficult to exclude with absolute certainty; nor had she any history of diphtheria. Although she had no signs of congenital syphilis and a negative W.R. she was classified as syphilitic because her father had died of general paralysis, but I feel less certain now that she was not a case of congenital complete heart block.

The effect of exercise was carefully observed on several occasions and she was unusual in that the ventricular rate could be increased to 70 (Fig. 10). The A/V ratio varied on different days but tended to be fairly constant during and after exercise on a particular day (see Table IX, where some rates recorded graphically are given). This relative constancy of the $A / V$ ratio suggests that both were being influenced by the same factor, possibly by the carbon dioxide content of the blood.

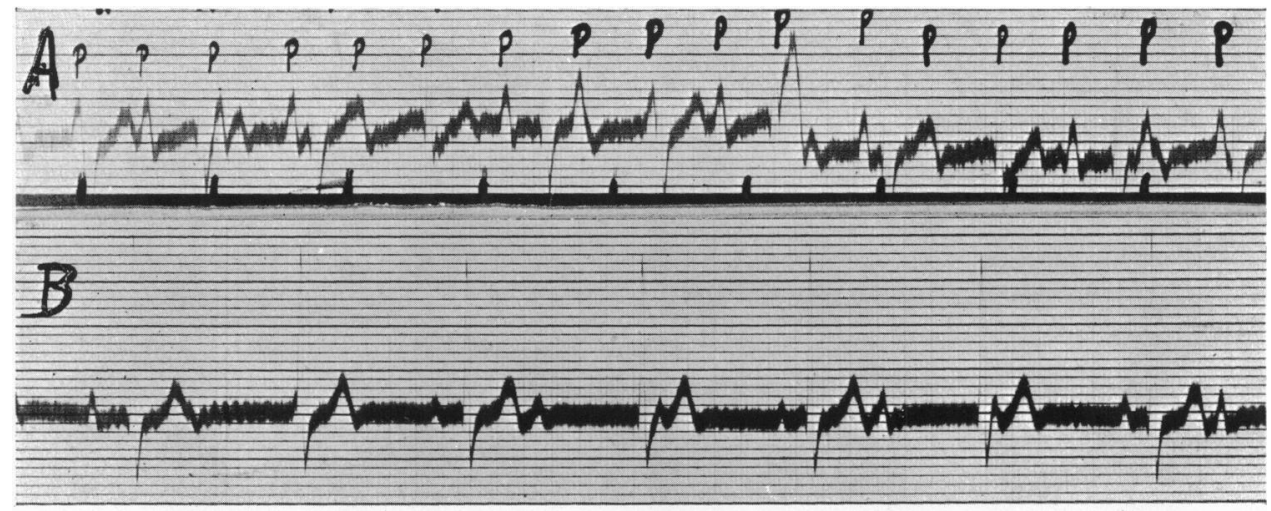

FIG. 10.-Complete heart block of unknown actiology (? congenital syphilitic) with a relatively rapid rate of 48 at rest (B) and a faster rate of 70 after exercise (A) from Case 159 . In (A), which is lead $I$, the $P$ waves have been marked; (B) is lead II. The time marker in (A) has been inked in to indicate seconds.

TABLE IX

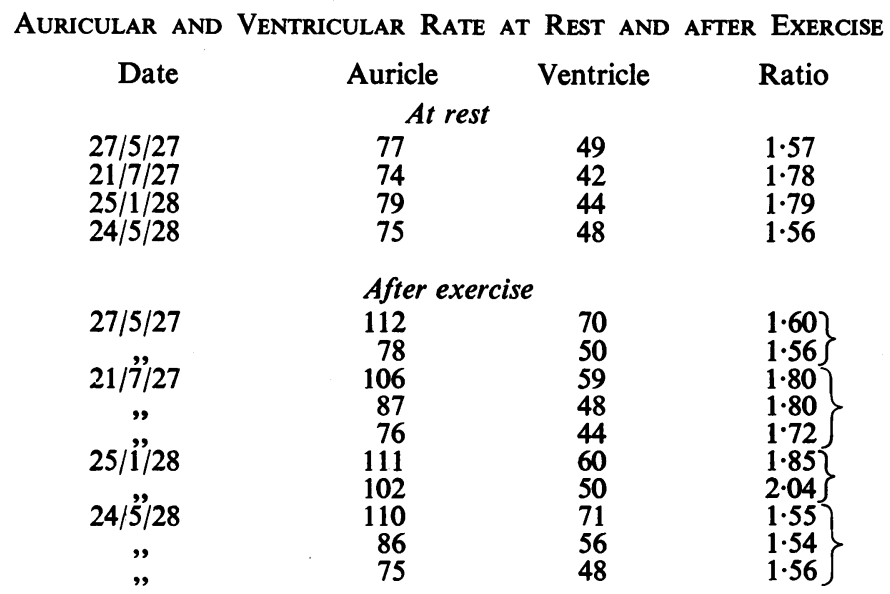

Dr. Suzman's Case. Stokes-Adams Attacks with Paroxysmal Heart Block (Complete)

The following patient, notes and records of whom have kindly been lent me by Dr. S. Suzman, had Stokes-Adams attacks due to ventricular standstill without any evidence of heart block except 
for a few minutes after a recorded Stokes-Adams attack. She did have bundle branch block but this was not persistent.

In 1937, when she was 64, she had her first attack of gall-stone colic and jaundice. In April 1941 she noticed she was short of breath and in August she became giddy and collapsed. In September, after another collapse, she was admitted to Guy's Hospital and diagnosed by Dr. Suzman as having Stokes-Adams attacks; she had bundle branch block (B.B.Bl.) with a P-R interval of 0.17 sec. Attacks were frequent enough for Dr. Suzman to hope for a graphic record, and after waiting some hours with everything ready he succeeded.

Before the attack there was B.B.Bl. with a normal P-R interval; in the attack there was ventricular standstill for nearly 30 seconds; and after the attack there was probably complete heart block lasting for at least a minute. At this stage no further film was available and the next day there was again B.B.Bl. with a P-R interval of $0.17 \mathrm{sec}$. She was discharged soon after and during the next month cardiograms taken while she was an out-patient were normal in every way except for rather low $T$ waves, the $P-R$ interval being $0 \cdot 16$ sec.

In January 1942 she was admitted to another hospital, and in view of her recurrent attacks of colic it was decided to remove the gall bladder, and this was followed by a second operation three weeks later for localized peritonitis. She was home well in April. During this stormy period her heart rate was regular and 70-90 a minute, except for some days after her operation, when it rose to 120, and no attention would have been drawn to her heart apart from the recent history of the attacks, which did not recur. Throughout her stay she took ephedrin, 1/2 grain daily. Her heart was enlarged $(16.5 \mathrm{~cm}$. m.t.d. in a chest of $26 \mathrm{~cm}$.). The B.P. was $110 / 70$. 